\title{
A Step by Step Methodology for Building Sustainable Cementitious Matrices
}

\author{
Styliani Papatzani ${ }^{1,2, *(1)}$ and Kevin Paine ${ }^{3(1)}$ \\ 1 Department of Mathematics and Engineering Sciences, Hellenic Army Academy, Evelpidon Avenue, \\ 16672 Vari Attika, Greece \\ 2 Directorate for the Restoration of Byzantine \& Post-Byzantine Monuments, Hellenic Ministry of Culture, \\ Tzireon 8-10, 11742 Athens, Greece \\ 3 BRE Centre for Innovative Construction Materials, University of Bath, Bath BA2 7AY, UK; k.paine@bath.ac.uk \\ * Correspondence: spapatzani@sse.gr
}

Received: 30 March 2020; Accepted: 20 April 2020; Published: 24 April 2020

check for updates

Featured Application: A formulation and testing protocol for the development of low Portland cement content cementitious binders.

\begin{abstract}
In an effort to produce cost-effective and environmentally friendly cementitious binders. mainly ternary (Portland cement + limestone + pozzolanas) formulations have been investigated so far. Various proportions of constituents have been suggested, all, however, employing typical Portland cement (PC) substitution rates, as prescribed by the current codes. With the current paper a step by step methodology on developing low carbon footprint binary, ternary and quaternary cementitious binders is presented (PC replacement up to 57\%). Best performing binary (60\% PC and $40 \%$ LS (limestone)) and ternary formulations (60\% PC, 20\% LS, $20 \%$ FA (fly ash) or $43 \%$ PC, $20 \%$ LS $37 \% \mathrm{FA}$ ) were selected on the grounds of sustainability and strength development and were further optimized with the addition of silica fume. For the first time a protocol for successfully selecting and testing binders was discussed and the combined effect of highly pozzolanic constituents in low PC content formulations was assessed and a number of successful matrices were recommended. The present paper enriched the current state of the art in composite low carbon footprint cementitious binders and can serve as a basis for further enhancements by other researchers in the field.
\end{abstract}

Keywords: low PC clinker; Portland cement; limestone; fly ash; silica fume; compressive strength; TGA/dTG; PSD; SEM/EDX

\section{Introduction}

Concrete, and subsequently Portland cement, is one of the commodities whose demand is ever increasing. According to the 2050 projections of CEMBUREAU, developing countries and emerging markets such as India and China are expected to need almost six billion tonnes of cement by the year 2050 [1]. Taking into consideration that production of cement is a major cause for carbon dioxide emissions, accountable for about $5-8 \%$ of anthropogenic $\mathrm{CO}_{2}$ emissions worldwide, concrete and cement research has been focusing on the production of low Portland cement formulations using supplementary cementitious materials, such as limestone, fly ash, ground granulated blast furnace slag and silica fume.

Although the present research is focused and based on European Standards it should be noted that a global shift towards performance based rather than prescriptive specifications (composition based formulations) can be observed. In fact, particularly with respect to fly ash addition, the American Concrete Institute suggests a maximum limit of $35 \%$ of fly ash addition in binary compositions while 
the need for admixtures is stressed [2]. Still, this limitation can be considered very conservative according to the National Ready Mixed Concrete Association, claiming that prescriptive specifications limit the opportunities to reduce the environmental impact of concrete. According to research carried out the greatest occurrence in specifications is the restriction to the quantities of Supplementary Cementitious Materials (SCMs) (85\% occurrence) [3]. The general consensus, therefore is to aim at specific performance, e.g., to limit the cement content, maximize the use of SCM, target specific strengths, curing time, slump, water-to-cementitious materials ratio in order to design the desired cement blend and concrete mix. This will effectively extend the allowable limits of the "code prescribed permissible" amounts of SCMs in concrete mixes, creating a gap in the current knowledge on low carbon footprint formulations containing more than two constituents.

Furthermore, the evolution of nanotechnology, has not only rendered monitoring of matter, at a scale marginally above the atomic, possible, but has also revolutionized cement science, producing novel cements and concretes of superior strength and durability [4,5]. Under the European Union FP7 project (FIBCEM), various nanoparticles (commercially available or produced by the project partners) were tested in cementitious matrices at the University of Bath, in an effort to produce low carbon footprint cements [6-10]. For this, the amount of Portland cement (PC) had to be limited and supplementary cementitious materials had to be added, forming blended cementitious matrices.

Although the value of hybrid binders is greatly appreciated [11] and an extensive number of studies have been carried out in an effort to understand possible synergies between constituent materials such as fly ash and limestone in ternary blends [12] or to determine the reactivity of pozzolanic materials [13] in blended cements, there is still limited research on the synergies and material reactivities in very low PC content cementitious matrices. That is to say, research presented to date, investigates the synergistic effect of constituent materials for up to 20\% PC replacement [14] or even higher PC replacement rates (55\% PC and 35\% fly ash and silica fume) but having a very low water to binder ratio (0.17) [15]. Qualitative characteristics of the hydration products resulting from the binary combinations of PC with either fly ash (FA) or silica fume $(\mu S)$ or limestone (LS) have been studied in greater detail by Lothenbach et al. [16]. Although there are many publications on binary systems, i.e., studies on various contents of FA or $\mu \mathrm{S}$ or LS Portland cements, there is limited published research on ternary and above systems. It has been found that in ternary cements containing PC, FA and LS, LS played a dual role; LS (i) contributed as a filler and (ii) participated in chemical reactions with the aluminate hydrates from the PC hydration [12,17]. In addition, following a study of eight different combinations of FA and LS content combined with PC, this team of researchers concluded that the consumption of $\mathrm{Ca}(\mathrm{OH})_{2}$ was more pronounced for the 30\%FA 5\%LS and 65\% PC blend rather than the 35\%FA and $65 \% \mathrm{PC}$ blend and was related to the carboaluminates formation and consequently LS appears to interfere with pozzolanic reactions. Consequently, with respect to compressive and flexural strength they inferred that although a $5 \%$ replacement of cement by LS reduced the strength of the formulation, a $5 \%$ addition of LS to $30 \% \mathrm{FA}$ and $65 \% \mathrm{PC}$ blend, will not cause strength reduction.

Furthermore, several research papers have reported a number of benefits of the combined effect of FA and $\mu \mathrm{S}$ on Portland cement blends such as increased early age compressive strength and slump of concretes [18]. Moreover, the $\mathrm{C} / \mathrm{S}$ ratio decreased with increasing $\mu \mathrm{S}$ content, which effectively caused an increase in compressive strength. Lastly, the maximum strength was obtained for the PC50FA40 $\mu$ S10 formulation.

It is interesting to note that although very few studies have been reported on ternary cement blends, no studies have been found on quaternary cement blends containing all the above-mentioned elements, that is to say PC, FA, LS and $\mu$ S. In fact, recently published reviews recognize the need for research on ternary and quaternary cementitious composites and on optimization of cement binders containing various pozzolanic materials at different proportions [19].

This gap is bridged by the current research. In fact a step by step methodology for the development of cementitious matrices is presented, based on strength and sustainability criteria. In greater detail, the following items were pursued in this study: 
- Low carbon footprint binary and ternary cementitious matrices (Figure 1) suitable for further modifications with the addition of silica fume were identified

- Best performing cementitious matrices were selected in terms of embodied energy and compressive strength

- Divergent results on the effect of the addition of limestone in composite cement binders were clarified

- The pozzolanic reactivity in ternary and quaternary cement paste formulations was investigated

- The combined effect of highly pozzolanic constituents in low PC content formulations was assessed

- The current knowledge on cement binder optimization was broadened.

In greater detail, apart from the industrial cement CEM II/A-L42.5 conforming to BS EN 197-1 [20] which was studied on its own, given the name B1 in the binary combinations (Figure 1) three more binary limestone-cement combinations were created with reduced Portland cement (PC) content in a gradual manner (B2 contained 80\% PC, B3 contained 70\%PC and B10 contained $60 \% \mathrm{PC}$. At the same time, ternary blended cements were studied at various fly ash contents starting from $20 \%$. Then a $35 \%$ FA content formulation was studied in two different pastes (B5 and B8). The specific amount is the upper limit according to ACI [2] for normal other than mass concretes in binary combinations and with respect to the European Standards used in this research, according to BS EN 197-1 [20], the Portland cement (PC) clinker content should not be less than $65 \%$ in pozzolanic blends containing limestone. Therefore, the ternary ones pose a significant challenge due to the further reduction of PC content.

Next, the performance-based concept was adopted, using as key indicators the 28 day compressive strength of the ten formulations, the hydration reactivity at 7 and 28 days of curing and the embodied $\mathrm{CO}_{2}$, as a result of the reduction of PC content and increase in the limestone and fly ash content. Of the ten formulations, three were selected for scanning electron images in order to detect durability issues in the forms of microcracks, which were taken into consideration for the additional quaternary formulations.

\begin{tabular}{|c|c|c|}
\hline $\begin{array}{l}\text { Cementitious } \\
\text { matrices } \\
\text { (current } \\
\text { research) }\end{array}$ & $\begin{array}{c}\text { Selected } \\
\text { Cementitious } \\
\text { matrices } \\
\text { (current research) }\end{array}$ & $\begin{array}{c}\text { Nano-modified } \\
\text { cementitious matrices } \\
\text { (published research) }\end{array}$ \\
\hline $\begin{array}{ll}\mathbf{B} & \text { B1: PC86LS14 } \\
\mathbf{i} & \mathrm{B} 2: \mathrm{PC} 80 \mathrm{LS} 20 \\
\mathbf{n} & \\
\mathbf{a} & \text { B3: PC70LS30 } \\
\mathbf{r} & \text { B10: PC60LS40 } \\
\mathbf{y} & \end{array}$ & PC60LS40 & $\begin{array}{c}\text { Ternary formulations: } \\
\mathrm{PC}=60 \% \\
\mathrm{LS}+\mathrm{nC} 2 / \mathrm{nC} 3 / \mathrm{nC} 4=40 \%\end{array}$ \\
\hline $\begin{array}{ll} & \text { B4: PC66LS14FA20 } \\
\mathbf{T} & \\
\mathbf{e} & \text { B5: PC51LS14FA35 } \\
\mathbf{r} & \text { B6: PC36LS14FA50 } \\
\mathbf{n} & \text { B: PC60LS20FA20 } \\
\mathbf{a} & \\
\mathbf{r} & \text { B8: PC45LS20FA35 } \\
\mathbf{y} & \text { B9: PC30LS20FA50 }\end{array}$ & 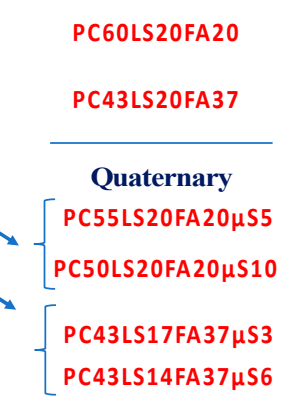 & \begin{tabular}{c|c}
$\begin{array}{c}\text { Quaternary formulations: } \\
\text { PC }=\mathbf{6 0} \%\end{array}$ & $\begin{array}{c}\text { Quaternary formulations: } \\
\mathbf{P C}=\mathbf{4 3} \%\end{array}$ \\
FA+LS+ nanoparticles=40\% & FA+LS+ nanoparticles=57\% \\
\end{tabular} \\
\hline
\end{tabular}

Figure 1. Development of binary, ternary and quaternary cementitious matrices in the current research and their enhancement with the incorporation of nanoparticles in published research.

The last step included fine tuning of the selected formulations by increasing the FA content to $37 \%$ for one of the ternary formulations, yielding; PC60LS40, PC60LS20FA20 and PC43LS20FA37. The latter two formulations were further investigated after the addition of two different proportions of silica fume (formulations typed in red in Figure 1). 
The resulting matrices were analyzed again against the key indicators determined above; compressive strength 7, 28 and 56 days of curing, the hydration reactivity at 7, 28 and 56 days of curing, the embodied $\mathrm{CO}_{2}$ and scanning electron imaging for microstructural defects, which could undermine durability. All the above, have been studied and analyzed in the subsequent sections, which paved the way for further modifications with the use of various nanoparticles (Figure 1).

\section{Materials and Methods}

\subsection{Materials}

The following materials and any commercially available data are listed below. These materials were characterized with a selection of the techniques, before implemented in the various cement paste combinations:

- Portland limestone cement: CEM II/A-L42.5 conforming to BS EN 197-1, Blaine density $=525 \mathrm{~kg} / \mathrm{m}^{2}$, absolute density $=3060 \mathrm{~kg} / \mathrm{m}^{2}$, bulk density $=1100 \mathrm{~kg} / \mathrm{m}^{2}$, clinker composition: $70 \% \mathrm{C}_{3} \mathrm{~S}, 4 \% \mathrm{C}_{2} \mathrm{~S}$, $9 \% \mathrm{C}_{3} \mathrm{~A}, 12 \% \mathrm{C}_{4} \mathrm{AF}$. CEM II/A-L42.5 contained $14 \%$ by mass limestone to which additional limestone was added

- $\quad$ Limestone (LS) (additional), conforming to BS EN 197-1

- Fly ash (FA), (siliceous) conforming to BS EN 450. The oxide composition provided by the material data sheet was: $53.5 \% \mathrm{SiO}_{2}, 34.3 \% \mathrm{Al}_{2} \mathrm{O}_{3}, 3,6 \% \mathrm{Fe}_{2} \mathrm{O}_{3}, 4.4 \% \mathrm{CaO}$

- Silica fume $(\mu \mathrm{S})$, in undensified dry form conforming to BS EN 13263. According to the material data sheet: specific surface area $=15-30 \mathrm{~m}^{2} / \mathrm{g}$, mean particle size $=0.15 \mu \mathrm{m}$.

\subsection{Preparation of Paste Combinations: Mixing, Casting, Demoulding, Curing}

The following methodology was adopted for the mixing procedure:

- $\quad$ Dry mixing of all powders with a spatula by hand.

- With the addition of water, the paste was mixed by a with an automatic dual shaft mixer at $1150 \mathrm{rpm}$ for $3 \mathrm{~min}$ for pastes up to $300 \mathrm{~g}$, time increasing with amounts of paste.

- Cylindrical specimens of $60 \mathrm{~mm}$ height and $30 \mathrm{~mm}$ diameter were prepared according to BS EN 196-1 [21].

- The cylindrical specimens of the initial cementitious matrices (B1-B10) were air-cured. However, when the final selection of binary and ternary matrices was made, the three selected cementitious matrices were reproduced, air-cured for 1 day, demoulded and then water cured until the day of testing.

\subsection{Step 1: Design of Cementitous Matrices}

The design of the cementitious matrices was carried out in a step-by-step manner and was aimed at designing and testing a low carbon dioxide footprint cement, which, at the same time, would have the highest possible compressive strength. As shown in Figure 2, according to BS EN 197-1 [20], for binary cements, containing clinker and limestone, only two types are allowed, CEM II/A-L and CEM II/B-L. In the former, the limestone content should not exceed $20 \%$, whereas in the latter, the limestone content should not exceed $35 \%$. Starting with B1, which was the as-received-cement by the industrial partner of the project FIBCEM, the amount of clinker was gradually reduced in the subsequent formulations (B2, B3 and B10).

Similarly, for ternary cementitious matrices containing clinker, fly ash and limestone, according to BS EN 197-1, the Portland cement (PC) clinker content should not be less than $65 \%$. Therefore, ternary combinations (B4, B5, B6, B7, B8 and B9) where designed with a PC clinker upper bound content of $65 \%$. 
Best performing pastes were identified and selected ternary formulations were subsequently optimized with the addition of silica fume, as the last step of the current research. The exact procedure is described in Sections 2.3.1 and 2.3.2, which is completed in Section 3, with the analysis of the results.

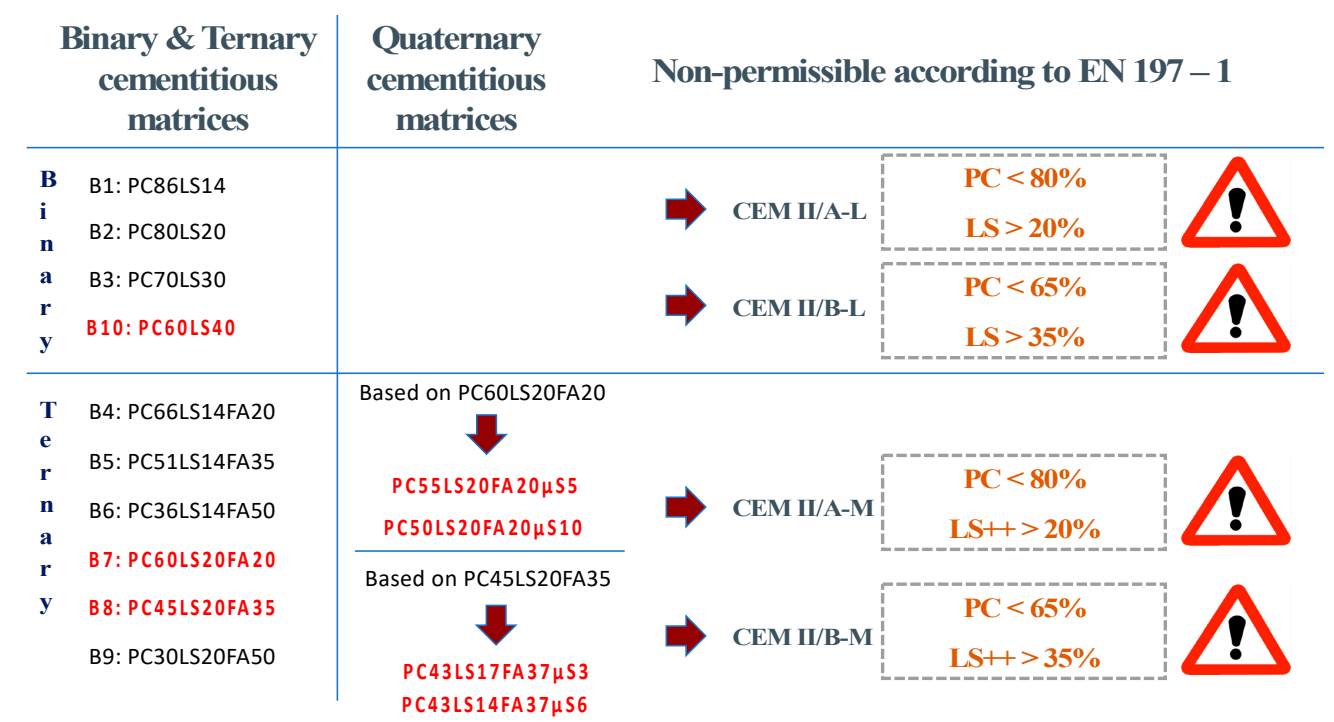

Figure 2. Binary, ternary and quaternary matrices developed for the current research compared with the limitations posed by Eurocode BS EN 197-1.

\subsubsection{Binary \& Ternary Cement Formulations}

The primary constituent is Portland limestone cement, CEMII/A-L42.5, which is a binary combination on its own, since it contains $86 \%$ of PC and $14 \%$ of LS, as verified by TGA/dTG, shown in Section 3.1.2. The first specimen produced, then, was named B1 and contained only CEMII. Eight more samples were produced next. B2 and B3 contained LS at $20 \%$ and $30 \%$, respectively. B4 to B9 represented ternary formulations of PC, LS and FA. All 9 initial bases were mixed at a water to binder $(\mathrm{w} / \mathrm{b})$ ratio of 0.3 . The exact proportions are shown in Table 1 that follows:

Table 1. Binary and ternary initial cement paste formulations-Mix Proportions \% by total mass of binder.

\begin{tabular}{ccccc}
\hline Sample & PC (\%) & LS (\%) & FA (\%) & w/b \\
\hline B1-PC86LS14 & 86 & 14 & 0.0 & 0.3 \\
B2-PC80LS20 & 80 & 20 & 0.0 & 0.3 \\
B3-PC70LS30 & 70 & 30 & 0.0 & 0.3 \\
B4-PC66LS14FA20 & 66 & 14 & 20 & 0.3 \\
B5-PC51LS14FA35 & 51 & 14 & 35 & 0.3 \\
B6-PC36LS14FA50 & 36 & 14 & 50 & 0.3 \\
B7-PC60LS20FA20 & 60 & 20 & 20 & 0.3 \\
B8-PC45LS20FA35 & 45 & 20 & 35 & 0.3 \\
B9-PC30LS20FA50 & 30 & 20 & 50 & 0.3 \\
B10-PC60LS40 & 60 & 40 & 0.0 & 0.3 \\
\hline
\end{tabular}

\subsubsection{Quaternary Cement Formulations}

B7 and B8 were found to perform best as will be discussed they were further enhanced by the addition of $\mu \mathrm{S}$. Initially, two quaternary formulations, having $60 \%$ PC by mass, in which the $\mu \mathrm{S}$ content was subtracted by the PC content, were designed as shown in Table 2. 
Table 2. Quaternary $\mu \mathrm{S}$ enhanced cement paste formulations-Mix Proportions \% by total mass of binder.

\begin{tabular}{cccccc}
\hline Sample & PC (\%) & LS (\%) & FA (\%) & $\boldsymbol{\mu S}(\%)$ & $\mathbf{w} / \mathbf{b}$ \\
\hline PC60LS20FA20 & 60 & 20 & 20 & 0.0 & 0.3 \\
PC55LS20FA20+5\% $\%$ S & 55 & 20 & 20 & 5.0 & 0.3 \\
PC50LS20FA20+10\% $\mathrm{SS}$ & 50 & 20 & 20 & 10 & 0.3 \\
\hline
\end{tabular}

Then, a lower PC content paste was designed, containing 43\% PC, 20\%LS and 37\% FA by mass as a reference paste, which was further enhanced by the addition of $\mu S$, subtracted by the LS content, this time, in order to maintain a w/b ratio of 0.3 , as shown in Table 3.

Table 3. Quaternary $\mu \mathrm{S}$ enhanced cement paste formulations-low PC-Mix Proportions \% by total mass of binder.

\begin{tabular}{cccccc}
\hline Sample & PC (\%) & LS (\%) & FA (\%) & $\boldsymbol{\mu S}(\mathbf{\%})$ & $\mathbf{w} / \mathbf{b}$ \\
\hline PC43LS20FA37 & 43 & 20 & 37 & 0.0 & 0.3 \\
PC43LS17FA37+3\% $\mu$ S & 43 & 17 & 37 & 3.0 & 0.3 \\
PC43LS14FA37+6\% $\mu$ S & 43 & 14 & 37 & 6.0 & 0.3 \\
\hline
\end{tabular}

\subsection{Preparation of Pastes for Characterization}

For the characterization of the pastes, arrest of hydration was performed following two different methodologies. In brief, if images were to be generated and the microstructure to be evaluated, such as SEM/FESEM and MIP, solvent exchange was the technique employed for the arrest of hydration. For experiments in which chemical reactions would occur or where the chemical composition had to be evaluated, such as TGA, XRD, the oven drying technique was adopted as explained in detail in [22]. For the SEM/FESEM and MIP studies, the samples were crashed and immersed in isopropanol for $48 \mathrm{~h}$. Isopropanol was selected as the most appropriate solvent according [23,24]. The samples were, then, vacuum dried for $24 \mathrm{~h}$. The cement paste samples were uncoated when examined at the SEM. For the chemical analyses studies the samples were crushed and placed in the oven at $60{ }^{\circ} \mathrm{C}$ for up to $24 \mathrm{~h}$. Then, they were ground and sieved through a $125 \mu \mathrm{m}$ sieve and placed back in the oven at $60{ }^{\circ} \mathrm{C}$ for another $24 \mathrm{~h}$. All samples were placed in the desiccator in a labelled air-tight container until they were analyzed. For the compressive strength tests, the three samples prepared for each paste formulation were removed from the curing tank a few minutes before being tested. Any uneven surfaces were levelled with a diamond saw, avoiding capping. Consecutively, the specimens were weighed and measured.

\subsection{Experimental Techniques}

The entire experimental program carried out in this research paper is summarized in Figure 3.

\subsubsection{Thermogravimetric Analyses and Differential Thermogravimetry (TGA/dTG)}

Thermogravimetric analyses were carried out using a TGA92 instrument (Setaram, Caluire, France). Approximately $20 \mathrm{mg}$ of each sample were placed in an alumina crucible and heated at a rate of $10^{\circ} \mathrm{C} / \mathrm{min}$ from $20^{\circ} \mathrm{C}$ to $1000^{\circ} \mathrm{C}$ under $100 \mathrm{~mL} / \mathrm{min}$ flow of inert nitrogen gas. Mass change, differential mass change and heat flow measurements were recorded and analyzed using the built-in software. The differential thermogravimetric curve (dTG) was derived by the TG curve. The first derivative curve was produced for the various samples tested and was used for comparisons instead of the mass loss curve, as it yields sharp distinctive peaks. 
A) Constituent materials

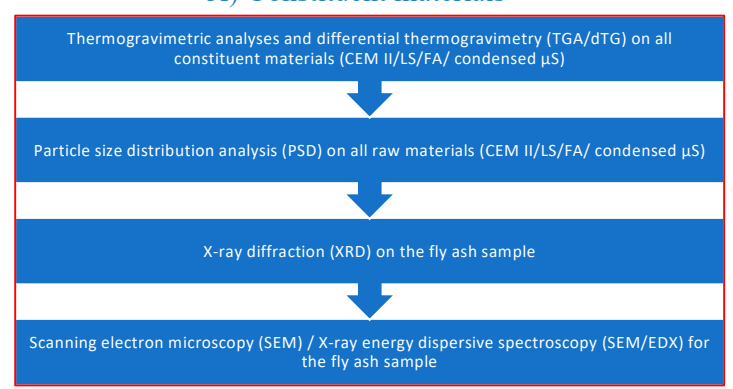

B) Binary and ternary cementitious matrices

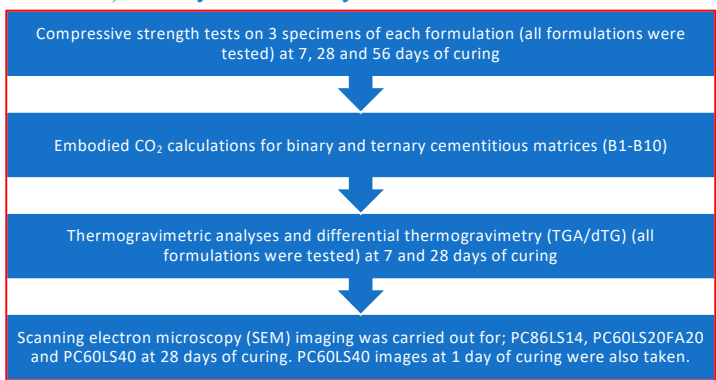

C) Quaternary cementitious matrices

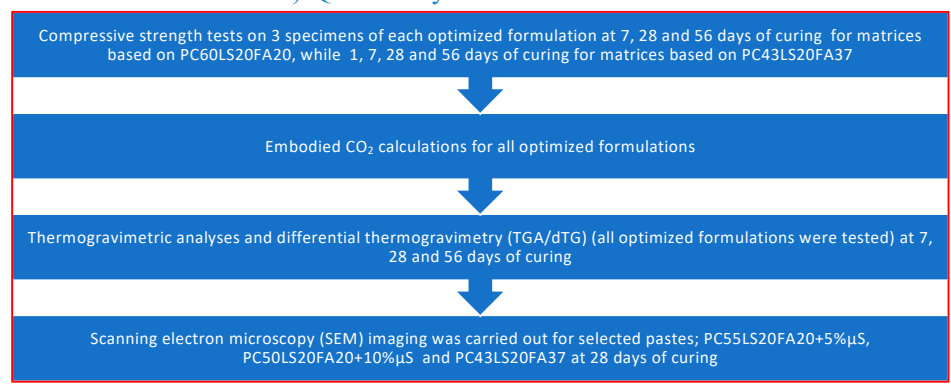

Figure 3. Overview of the experimental program.

TGA/dTG was carried out for both constituent materials and cement pastes. With respect to hardened cement pastes, three broad areas, can be distinguished by the TGA; the first one is related to the dehydration of C-S-H ettringite and monosulfate, between $100{ }^{\circ} \mathrm{C}$ and $200{ }^{\circ} \mathrm{C}$. It can be postulated that the greater the loss measured the greater the amount of $\mathrm{C}-\mathrm{S}-\mathrm{H}$ and ettringite was produced by the hydration of the paste.

The second area of interest is associated with the dehydroxylation of $\mathrm{Ca}(\mathrm{OH})_{2}$ between $400{ }^{\circ} \mathrm{C}$ and $510^{\circ} \mathrm{C}$. The amount of $\mathrm{Ca}(\mathrm{OH})_{2}$ present in the paste at different ages can be computed by the stoichiometric elaboration of the mass loss results within the specific temperature range [25].

The third area of interest is the decomposition of $\mathrm{CaCO}_{3}$ known as decarboxylation, occurring between $610{ }^{\circ} \mathrm{C}$ and $810{ }^{\circ} \mathrm{C}$. The amount of $\mathrm{CaCO}_{3}$ present in the paste at different ages can be computed by the stoichiometric elaboration of the mass loss results within the specific temperature range. If it is greater than the limestone content of the reference paste, it constitutes an indication of sample carbonation. Particularly for the quantification of $\mathrm{Ca}(\mathrm{OH})_{2}$, TGA is considered a very accurate technique [26], especially if coupled with XRD [27-30].

\subsubsection{Scanning Electron Microscopy (SEM)/X-Ray Energy Dispersive Spectroscopy (SEM/EDX)}

The surface morphology was observed with SEM. Back scattered micrographs of uncoated samples at various magnifications and beam currents were obtained using a Jeol $6480 \mathrm{LV}$ scanning electron microscope. For SEM/EDX elemental composition analyses sample was placed uncoated on a sheet of molybdenum for unbiased elemental analyses. A matrix of $5 \times 5$ spectra was acquired and the median of the elemental composition was presented.

\subsubsection{Particle Size Distribution Analysis (PSD)}

Particle size distribution analysis with optical system can provide the PSD of a wide range of scales of particles from $10 \mathrm{~nm}$ to $3 \mathrm{~mm}$. Particle size distribution analysis was carried out at the MANIT laboratory, Bhopal, India, using an LA950 Laser Scattering Particle Size Distribution Analyzer (Horiba, New Delhi, India). 


\subsubsection{X-Ray Diffraction (XRD)}

XRD measurements were performed for the FA using a D8 ADVANCE X-ray diffractometer (Bruker, Coventry, U.K.) with CuK $\alpha$ radiation. Spectra were obtained in the range $4^{\circ}<2 \theta<20^{\circ}$ at an angular step-size of $0.016^{\circ} 2 \theta$.

\subsubsection{Mechanical Properties Testing Techniques}

The strength of the supplied cement was validated according to BS EN 196-1 [21]. All samples were tested at a loading speed of $0.5 \mathrm{MPa} / \mathrm{s}$ on a $100 \mathrm{kN}$ servo hydraulic machine (Dartec, Stourbridge, U.K.). Mean strength values of the specimens tested were calculated.

\subsubsection{Carbon Dioxide $\left(\mathrm{CO}_{2}\right)$ Footprint}

Preliminary estimation of the $\mathrm{CO} 2$ footprint of the initial pastes was derived from compressive strength of cement pastes (MPa) evaluated against embodied $\mathrm{CO}_{2}$. $\left(\mathrm{ECO}_{2}\right)$. The levels of $\mathrm{ECO}_{2}$ have been agreed in the UK and are evaluated in terms of $\mathrm{kg} \mathrm{CO}_{2}$ per tonne of binding material [31].

- $\quad \mathrm{PC}=930 \mathrm{~kg} \mathrm{CO}_{2} /$ tonne

- $\quad$ FA from coal burning power generation $=4 \mathrm{~kg} \mathrm{CO}_{2} /$ tonne

- $\mathrm{LS}=32 \mathrm{~kg} \mathrm{CO} /$ tonne

It can be seen that in terms of $\mathrm{CO}_{2}$ footprint the use of FA as a supplementary cementitious material is beneficial. This is the reason for which it was used in the paste design despite of its shortage in the UK. Additionally:

- $\mu \mathrm{S}=14 \mathrm{~kg} \mathrm{CO} /$ tonne [32]

\section{Results and Discussion}

\subsection{Characterization of Constituent Materials}

All commercially available materials listed in Section 2.1 were characterized with a selection of techniques (PSD, TGA/dTG, XRD and SEM/EDX), before implemented in the cementitious matrices.

\subsubsection{PSD Results of CEM II/LS/FA/Condensed $\mu \mathrm{S}$}

The particle size distribution results of the four constituent materials reacted with water were prepared by colleagues in MANIT, India and are presented below. Results are typical for this type of industrially available materials, as can be seen in Table 4 and in the following Figures 4-7.

Table 4. PSD results of materials.

\begin{tabular}{cccccc}
\hline & Mean Size $(\mu \mathrm{m})$ & Mode Size $(\mu \mathrm{m})$ & Median Size $(\mu \mathrm{m})$ & Diameter at $\mathbf{1 0} \%(\mu \mathrm{m})$ & Diameter at $\mathbf{9 0} \%(\boldsymbol{\mu m})$ \\
\hline CEMII & 11.38 & 2.74 & 3.25 & 1.40 & 22.16 \\
LS & 12.14 & 2.44 & 3.21 & 1.36 & 31.89 \\
FA & 9.09 & 2.14 & 2.53 & 1.46 & 10.13 \\
$\mu$ S & 9.65 & 3.66 & 5.05 & 2.41 & 22.03 \\
\hline
\end{tabular}

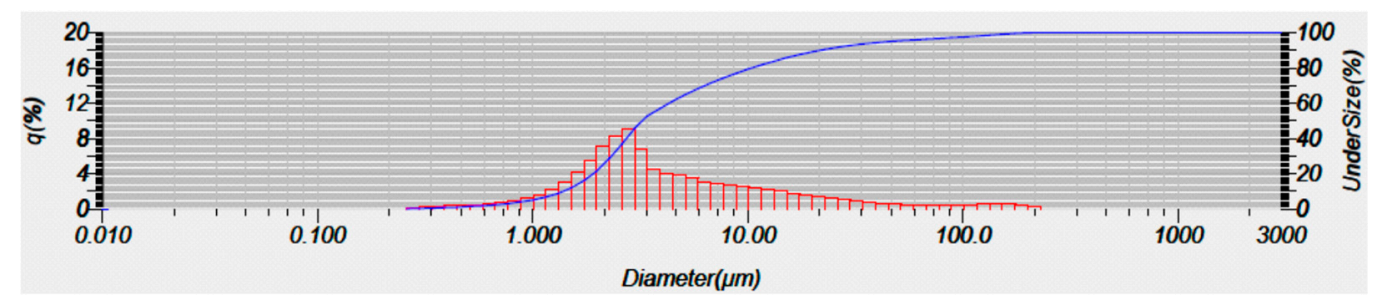

Figure 4. Normal distribution of CEMII. 


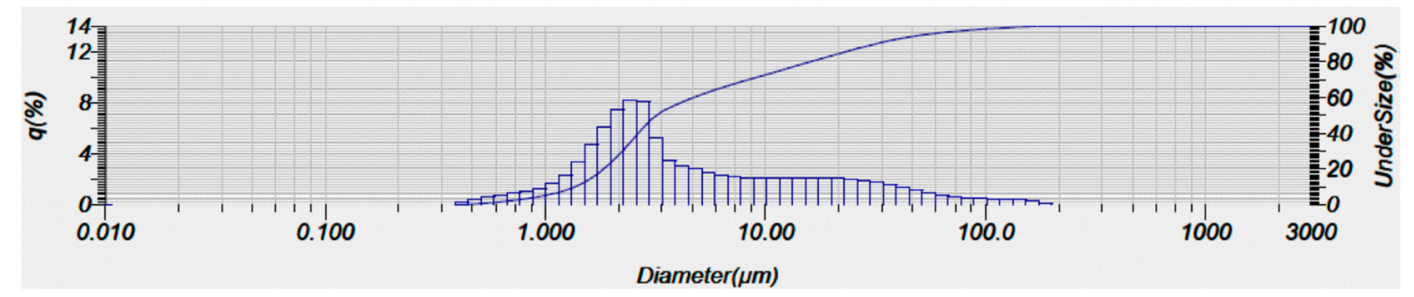

Figure 5. Normal distribution of LS.

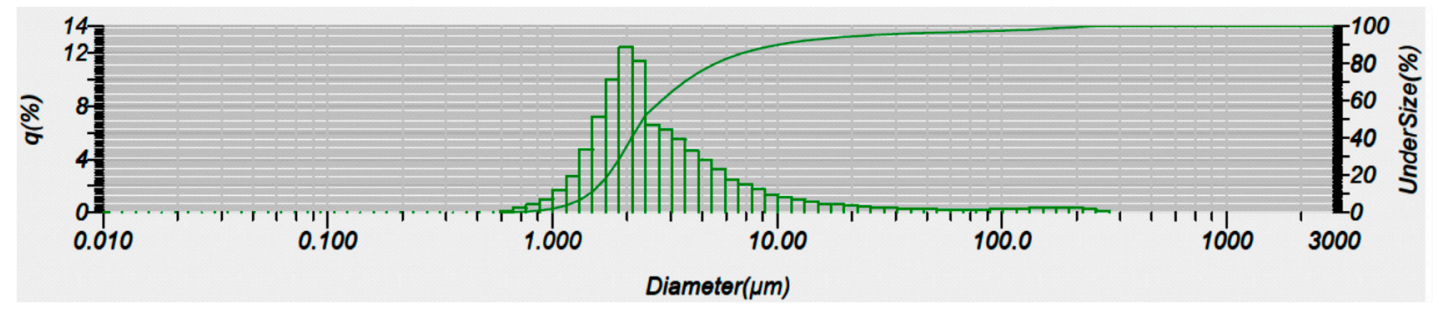

Figure 6. Normal distribution of FA.

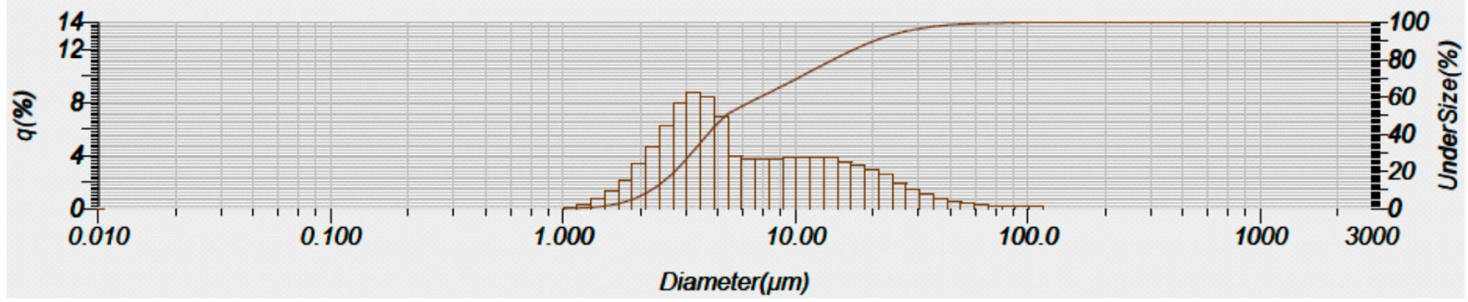

Figure 7. Normal distribution of $\mu S$.

\subsubsection{TGA Results of CEM II/LS/FA/ $\mu \mathrm{S}$}

The thermogravimetric analyses results of the four constituent materials are presented in Figure 8. It can be seen that practically the only mass loss upon heating is observed for, CEMII and LS, the differential mass loss of which was measured to be $42.4 \%$ and $5.95 \%$, respectively. The initial amount of $\mathrm{CaCO}_{3}$ was calculated via stoichiometry [25] and yielded $14 \%$ of $\mathrm{CaCO}_{3}$ present in CEMII and $97 \%$ in LS. Therefore, the LS powder is considered to be almost pure $\mathrm{CaCO}_{3}$ and the composition of CEMII is considered as $86 \%$ PC and $14 \%$ LS. The minor mass loss of FA with a peak at about $850{ }^{\circ} \mathrm{C}$ can be attributed to the volatile matter in the unburnt coal [33].

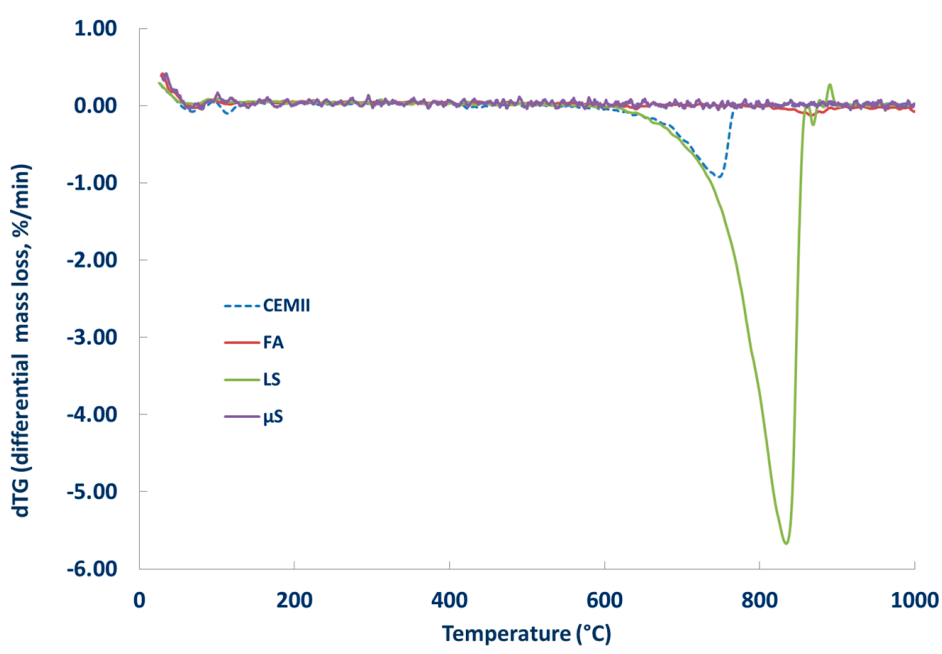

Figure 8. Differential mass loss of microsized constituent materials. 


\subsubsection{XRD and SEM/EDX results of FA}

Moreover, the different minerals present in the FA powder were determined by XRD crystallographic analysis [34]. As shown in Figure 9, mullite, quartz, hematite, lime and calcium carbonate are present [9].

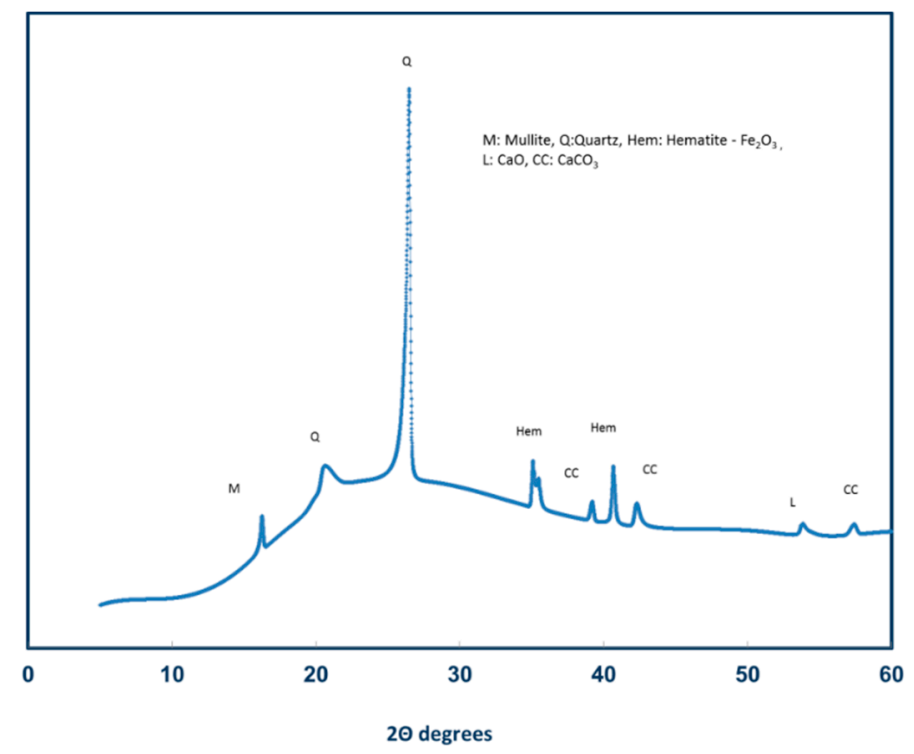

Figure 9. XRD diffraction pattern of FA.

Lastly, 20 spectra were acquired via the SEM/EDX carried out on a FA sample, five of which are indicatively shown in Table 5. The presence of sulphur which has been reported to increase the ettringite formation during cement hydration was confirmed [35].

Table 5. SEM/EDX counts summary (\% atomic) of FA.

\begin{tabular}{cccccccccccccc}
\hline \multicolumn{11}{c}{ FA-All Results in Atomic \% Normalized to $\mathbf{1 0 0 \%}$} \\
\hline Spectrum & $\mathbf{C}$ & $\mathbf{O}$ & $\mathbf{N a}$ & $\mathbf{M g}$ & $\mathbf{A l}$ & $\mathbf{S i}$ & $\mathbf{P}$ & $\mathbf{S}$ & $\mathbf{C l}$ & $\mathbf{K}$ & $\mathbf{C a}$ & $\mathbf{T i}$ & $\mathbf{F e}$ \\
$(1,1)$ & 16.73 & 55.58 & 0.49 & 0.74 & 8.84 & 13.62 & 0.00 & 0.14 & 0.04 & 0.82 & 1.06 & 0.28 & 1.66 \\
$(2,1)$ & 18.86 & 52.35 & 0.06 & 0.72 & 12.23 & 13.31 & 0.01 & 0.10 & 0.02 & 0.33 & 1.23 & 0.02 & 0.80 \\
$(3,1)$ & 15.07 & 55.63 & 0.36 & 0.7 & 11.54 & 12.52 & 0.07 & 0.19 & 0.02 & 0.52 & 1.26 & 0.69 & 1.48 \\
$(4,1)$ & 5.41 & 60.94 & 0.67 & 0.96 & 10.96 & 16.5 & 0.17 & 0.19 & 0.06 & 1.07 & 1.15 & 0.33 & 1.70 \\
$(5,1)$ & 8.57 & 59.8 & 0.35 & 0.52 & 12.34 & 15.08 & 0.1 & 0.09 & 0.05 & 0.60 & 1.45 & 0.21 & 0.94 \\
Mean & 16.97 & 55.1 & 0.52 & 0.77 & 8.13 & 12.62 & 0.09 & 0.21 & 0.01 & 0.62 & 1.35 & 0.20 & 3.42 \\
Stdv & 6.48 & 3.05 & 0.17 & 0.52 & 2.37 & 2.36 & 0.08 & 0.21 & 0.05 & 0.18 & 1.55 & 0.14 & 3.29 \\
\hline
\end{tabular}

3.2. Step 2: Testing and Step 3: Selecting best Performing Pastes of the Binary and Ternary Cementitious Matrices

After Step 1 was presented in Section 2.3, in which the concept behind the designing of cementitious matrices was unfolded, in this section the results of sample testing and selecting best performing pastes is analyzed. Apart from the pure CEMII paste (B1), nine additional Portland limestone cement initial formulations (B2-10) were designed, containing different proportions of CEMII and limestone or CEMII, limestone and fly ash, as already discussed. Best performing pastes were judged according to the delivered compressive strength and embodied carbon dioxide content. As shown below, best relations between strength and embodied $\mathrm{CO}_{2}$ were obtained for B7: PC60LS20FA20 and B8: PC45LS20FA35, which delivering $80 \mathrm{MPa} / \mathrm{t} / \mathrm{t}$ and $110 \mathrm{MPa} / \mathrm{t} / \mathrm{t}$, respectively. These two formulations were selected to be further optimized, later, forming the quaternary cementitious matrices. Thermal analyses 
were also performed on all initial cementitious matrices (B1-B10). All results are presented in the following sections.

\subsubsection{Compressive Strength of Binary and Ternary Cementitious Matrices (B1-B10)}

Binary and ternary cementitious matrices (B1-B10) were tested in compression at day 7, 28 and 56, as shown in Figure 10.

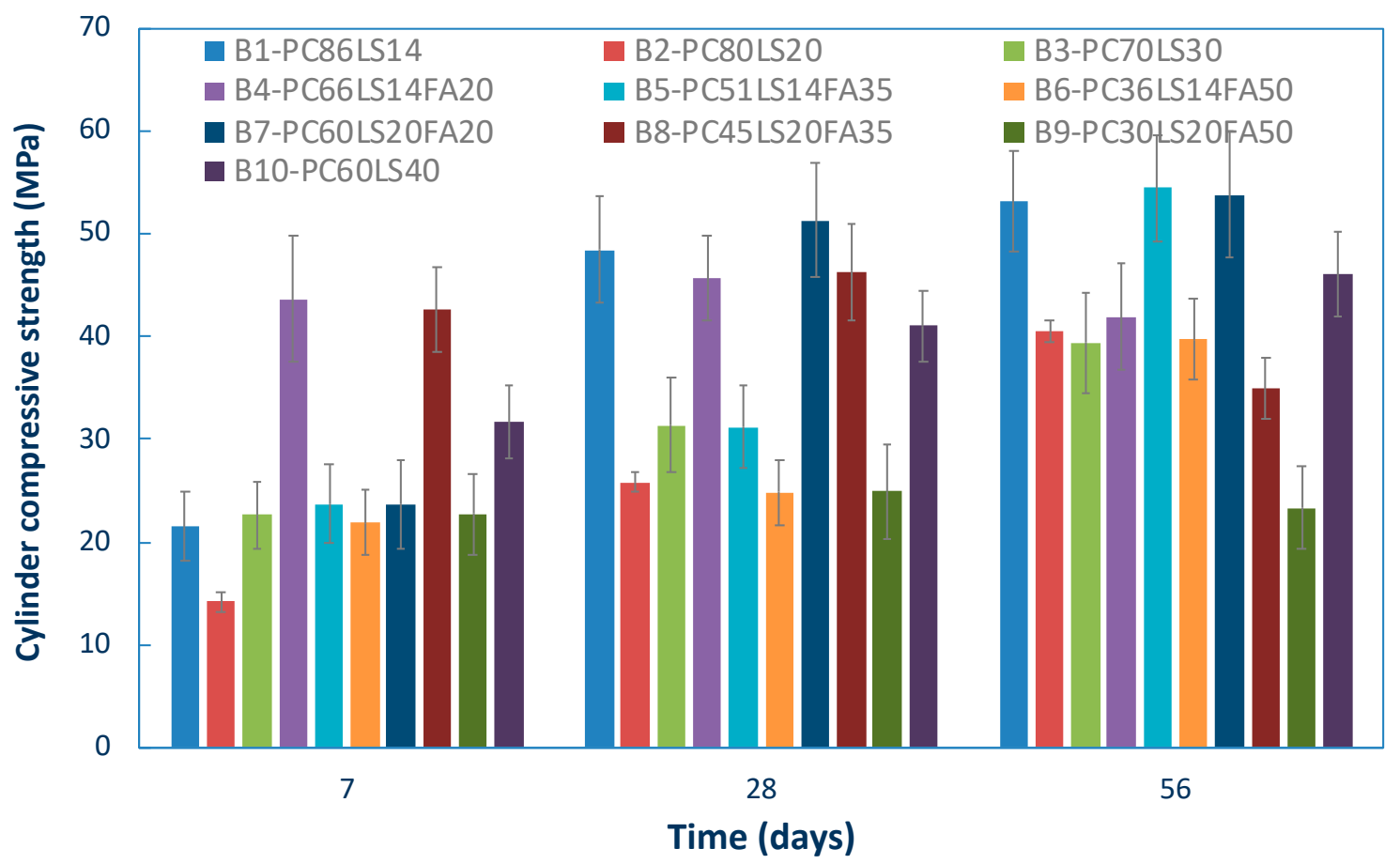

Figure 10. Cylinder compressive strength of binary and ternary cementitious matrices (B1-B10).

The compressive strength tests allowed the rejection of B1, B2 and B3 on the grounds of high PC content and performance that can be achieved with greener combinations. For example, B5 showed better long term performance than B1. B9 was also rejected due to poor performance.

\subsubsection{Embodied $\mathrm{CO}_{2}$ of Binary and Ternary Cementitious Matrices (B1-B10)}

Then, the sustainability potential of all binary and ternary cementitious matrices was calculated with respect to the embodied $\mathrm{CO}_{2}$ (E.CO $\mathrm{CO}_{2}$ ) of PC (930 $\mathrm{kg} \mathrm{CO}_{2} /$ tonne), $\mathrm{LS}$ (32 $\mathrm{kg} \mathrm{CO}_{2} /$ tonne) and FA (4 $\mathrm{kg} \mathrm{CO} /$ tonne) [36,37]. The results are presented in Table 6.

Table 6. Embodied $\mathrm{CO}_{2}$ associated with strength of binary \& ternary cementitious matrices.

\begin{tabular}{|c|c|c|c|c|c|c|c|}
\hline Sample & $\begin{array}{l}\text { Formulation } \\
\text { Composition }\end{array}$ & $\begin{array}{c}\mathrm{PC} \\
\mathrm{E} . \mathrm{CO}_{2} \\
\text { (kg/tonne) }\end{array}$ & $\begin{array}{c}\mathrm{LS} \mathrm{E.CO} \\
\text { (kg/tonne) }\end{array}$ & $\begin{array}{c}\text { FA E.CO } \\
\text { (kg/tonne) }\end{array}$ & $\begin{array}{l}\text { Total E. } \mathrm{CO}_{2} \\
\text { (kg/tonne) }\end{array}$ & $\begin{array}{l}\text { Compression Strength } \\
28 \text { Days (MPa) }\end{array}$ & $\begin{array}{l}\text { Strength/E.CO } \\
(\mathrm{MPa} / \mathrm{kg} / \text { tonne })\end{array}$ \\
\hline B1 & PC86LS14 & 799.8 & 4.5 & 0.0 & 804.3 & 48.4 & 0.06 \\
\hline B2 & PC80LS20 & 744.0 & 6.4 & 0.0 & 750.4 & 25.8 & 0.03 \\
\hline B3 & PC70LS30 & 651.0 & 9.6 & 0.0 & 660.6 & 31.4 & 0.05 \\
\hline B4 & PC66LS14FA20 & 613.8 & 4.5 & 0.8 & 619.1 & 45.6 & 0.07 \\
\hline B7 & PC60LS20FA20 & 558.0 & 6.4 & 0.8 & 565.2 & 51.3 & 0.09 \\
\hline B8 & PC45LS20FA35 & 418.5 & 6.4 & 1.4 & 426.3 & 46.3 & 0.11 \\
\hline B9 & PC30LS20FA50 & 279.0 & 6.4 & 2.0 & 287.4 & 24.9 & 0.09 \\
\hline B10 & PC60LS40 & 559.8 & 12.8 & 0.0 & 572.6 & 41.0 & 0.09 \\
\hline
\end{tabular}


By observing the results provided in Table 6, it is evident that B6 to B10 had the lowest total E. $\mathrm{CO}_{2}$. Furthermore, B7, B8 and B10 had the lower environmental impact and exhibited the highest mechanical properties in terms of compressive strength compared amongst the initial pastes. As an effect, B7, B8 and B10 were the three selected bases for further optimization with the addition of microsized elements.

\subsubsection{Thermal Analyses of Binary and Ternary Cementitious Matrices (B1-B10)}

TG analyses were carried out at 7 and 28 days, the results of which are shown in Figures 11 and 12. It should be noted that initially the first nine bases were dry cured (B10 was only water cured), however none had carbonated since the $\mathrm{CaCO}_{3}$ content is lower than the initial LS content in the paste.

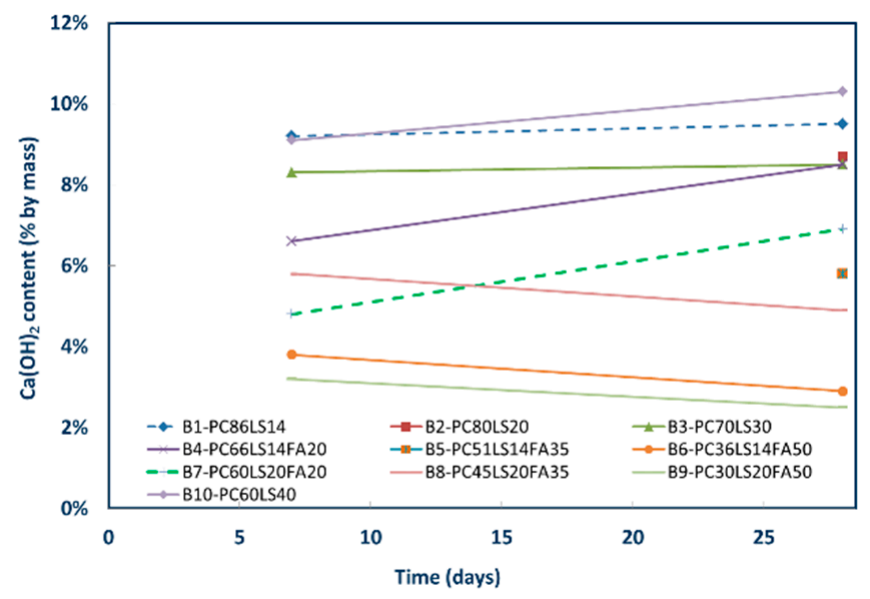

Figure 11. $\mathrm{Ca}(\mathrm{OH})_{2}$ content of binary and ternary cementitious matrices.

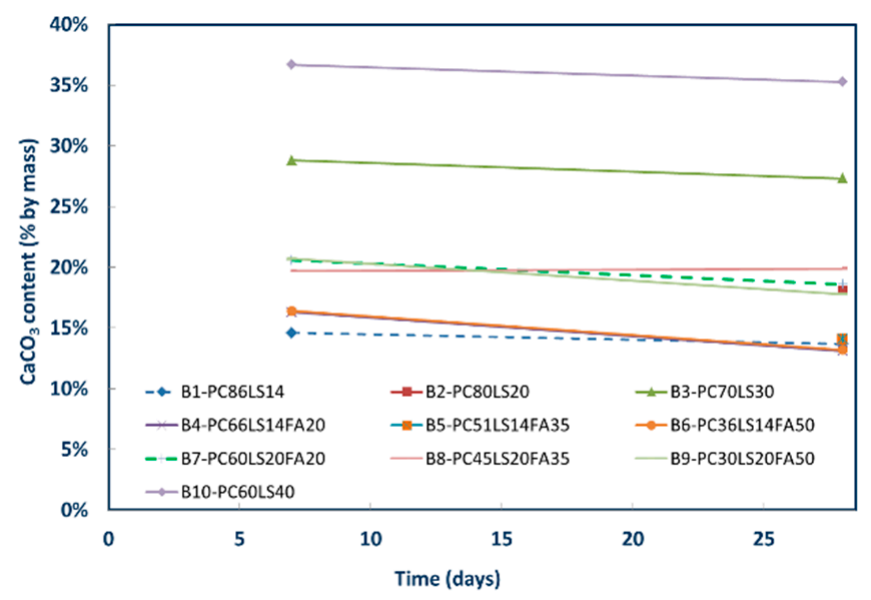

Figure 12. $\mathrm{CaCO}_{3}$ content of binary and ternary cementitious matrices.

In addition to the thermal analyses carried out at day 7 and day 28 , the three selected cementitious matrices (PC60LS40, PC60LS20FA20 and PC43LS20FA37), were reproduced, water cured after day 1 and TG analyses were carried out at day 1, 7, 28 and 56. For PC60LS40, TG analyses were carried out at day 90, as well. At this point, the $\mathrm{Ca}(\mathrm{OH})_{2}$ consumption will be discussed (Table 7 ) in an effort to shed more light into the hydration processes. To begin with, it can be noticed that until day 28 , that PC continues hydrating, the $\mathrm{Ca}(\mathrm{OH})_{2}$ content of PC60LS40 increased and from then after it remained almost constant. It can be claimed, therefore, that the presence of FA in PC60LS20FA20 increased the consumption of the $\mathrm{Ca}(\mathrm{OH})_{2}$ content significantly over all ages. 
Table 7. Comparison of the $\mathrm{Ca}(\mathrm{OH})_{2}$ content of the selected bases.

\begin{tabular}{ccccc}
\hline & $\mathbf{1}$ & $\mathbf{7}$ & $\mathbf{2 8}$ & $\mathbf{5 6}$ \\
\hline PC60LS40 & $7.5 \%$ & $9.1 \%$ & $10.3 \%$ & $10.6 \%$ \\
PC60LS20FA20 & $7.2 \%$ & $8.1 \%$ & $8.2 \%$ & $8.1 \%$ \\
PC43LS20FA37 & $4.0 \%$ & $6.0 \%$ & $5.9 \%$ & $1.5 \%$ \\
\hline
\end{tabular}

As demonstrated in Table 7, PC60LS40 at day 1 contained $7.5 \% \mathrm{Ca}(\mathrm{OH})_{2}$ and $9.1 \%$ at day 7 . For the first two pastes, PC60LS40 and PC60LS20FA20, which have the same PC content, the rate of hydration of PC at day 1 and 7 is expected to be essentially unaltered. However, it can be observed that at early ages, the $\mathrm{Ca}(\mathrm{OH})_{2}$ content of PC60LS20FA20 is significantly lower, particularly at day 7 . This is a strong indication that the pozzolanic activity of the FA present in this paste had already started by day 7, although it has been claimed that at high FA contents (PC45FA55) other researchers had noticed $\mathrm{Ca}(\mathrm{OH})_{2}$ consumption by day 3 [38]. Nonetheless, FA content is one matter and PC content is another. For this, the authors have adopted the PC/FA ratio, which is more representative in thermal analyses, together with the full formulation dosages, since FA is feeding from the $\mathrm{Ca}(\mathrm{OH})_{2}$ produced during cement hydration. The following observations were drawn:

- A paste containing $43 \% \mathrm{PC}$ would be expected to generate $43 / 60 \times 7.5 \%=5.4 \% \mathrm{Ca}(\mathrm{OH})_{2}$ based on PC60LS40 $\mathrm{Ca}(\mathrm{OH})_{2}$ content at day 1 .

- Also, a paste containing $43 \% \mathrm{PC}$ would be expected to generate $43 / 60 \times 7.2 \%=5.2 \% \mathrm{Ca}(\mathrm{OH})_{2}$ based on PC60LS20FA20 $\mathrm{Ca}(\mathrm{OH})_{2}$ content at day 1.

- As shown in Table 7, PC43LS20FA37 contained $4.0 \% \mathrm{Ca}(\mathrm{OH})_{2}$ at day 1 . This indicates that the pozzolanic activity of a part of the FA present in the paste had already commenced.

- Inversely, a paste containing $43 \% \mathrm{PC}$ would be expected to generate $43 / 60 \times 9.1 \%=6.5 \% \mathrm{Ca}(\mathrm{OH})_{2}$ based on PC60LS40 $\mathrm{Ca}(\mathrm{OH})_{2}$ content at day 7 .

- A paste containing $43 \% \mathrm{PC}$ would be expected to generate $43 / 60 \times 8.1 \%=5.8 \% \mathrm{Ca}(\mathrm{OH})_{2}$ based on PC60LS20FA20 $\mathrm{Ca}(\mathrm{OH})_{2}$ content at day 7.

- As demonstrated in Table 7, PC43LS20FA37 contained $6.0 \% \mathrm{Ca}(\mathrm{OH})_{2}$ at day 7. This indicates that the pozzolanic activity of a part of the FA present in the paste had progressed by day 7 , but the reaction of the available FA particles could have been delayed.

- Continuing this train of thought, a paste containing 43\%PC would be expected to generate 43/60 $\times 10.3 \%=7.4 \% \mathrm{Ca}(\mathrm{OH})_{2}$ based on PC60LS40 $\mathrm{Ca}(\mathrm{OH})_{2}$ content at day 28 .

- Moreover, a paste containing $43 \% \mathrm{PC}$ would be expected to generate $43 / 60 \times 8.2 \%=5.9 \% \mathrm{Ca}(\mathrm{OH})_{2}$ based on PC60LS20FA20 $\mathrm{Ca}(\mathrm{OH})_{2}$ content at day 28.

- PC43LS20FA37 contained $5.9 \% \mathrm{Ca}(\mathrm{OH})_{2}$ at day 28 (Table 7), implying that almost half of the FA was unreacted by day 28 since the amount of $\mathrm{Ca}(\mathrm{OH})_{2}$ was equal to that of PC60LS20FA20.

- Also, a paste containing $43 \% \mathrm{PC}$ would be expected to generate $43 / 60 \times 10.6 \%=7.6 \% \mathrm{Ca}(\mathrm{OH})_{2}$ based on PC60LS40 $\mathrm{Ca}(\mathrm{OH})_{2}$ content at day 56.

- Lastly, a paste containing $43 \% \mathrm{PC}$ would be expected to generate $43 / 60 \times 8.1 \%=5.8 \% \mathrm{Ca}(\mathrm{OH})_{2}$ based on PC60LS20FA20 $\mathrm{Ca}(\mathrm{OH})_{2}$ content at day 56 .

PC43LS20FA37 contained $1.5 \% \mathrm{Ca}(\mathrm{OH})_{2}$ at day 56 (Table 7), implying that the remaining unreacted FA was engaged in reactions by day 56 . Although no carbonation was detected, even if that was the case, the amount of $\mathrm{Ca}(\mathrm{OH})_{2}$ at day 56 is that low that any increase due to carbonation would still be negligible.

3.2.4. Microstructural Characterization of Binary and Ternary Cementitious Matrices (B1, B7 and B10)

Backscattered (BSC) images were collected for PC86LS14 (B1), PC60LS20FA20 (B7) and PC60LS40 (B10) and are presented below. As illustrated in Figures 13-16, the microstructure of the PC86LS14, PC60LS20FA20 and PC60LS40 exhibited typical characteristics of such pastes at day 28. A number of 
$\mathrm{CaCO}_{3}$ flakes, $\mathrm{Ca}(\mathrm{CO})_{2}$ (annotated as $\mathrm{CH}$ ) crystals and nest-like C-S-H (annotated as $\mathrm{CSH}$ ) are shown in the PC/LS paste. In Figure 13, flake-like C-S-H is mainly detected and some crystals of $\mathrm{Ca}(\mathrm{CO})_{2}$ covered by $\mathrm{C}-\mathrm{S}-\mathrm{H}$ are also noted. The presence of microcracks is visible as well.
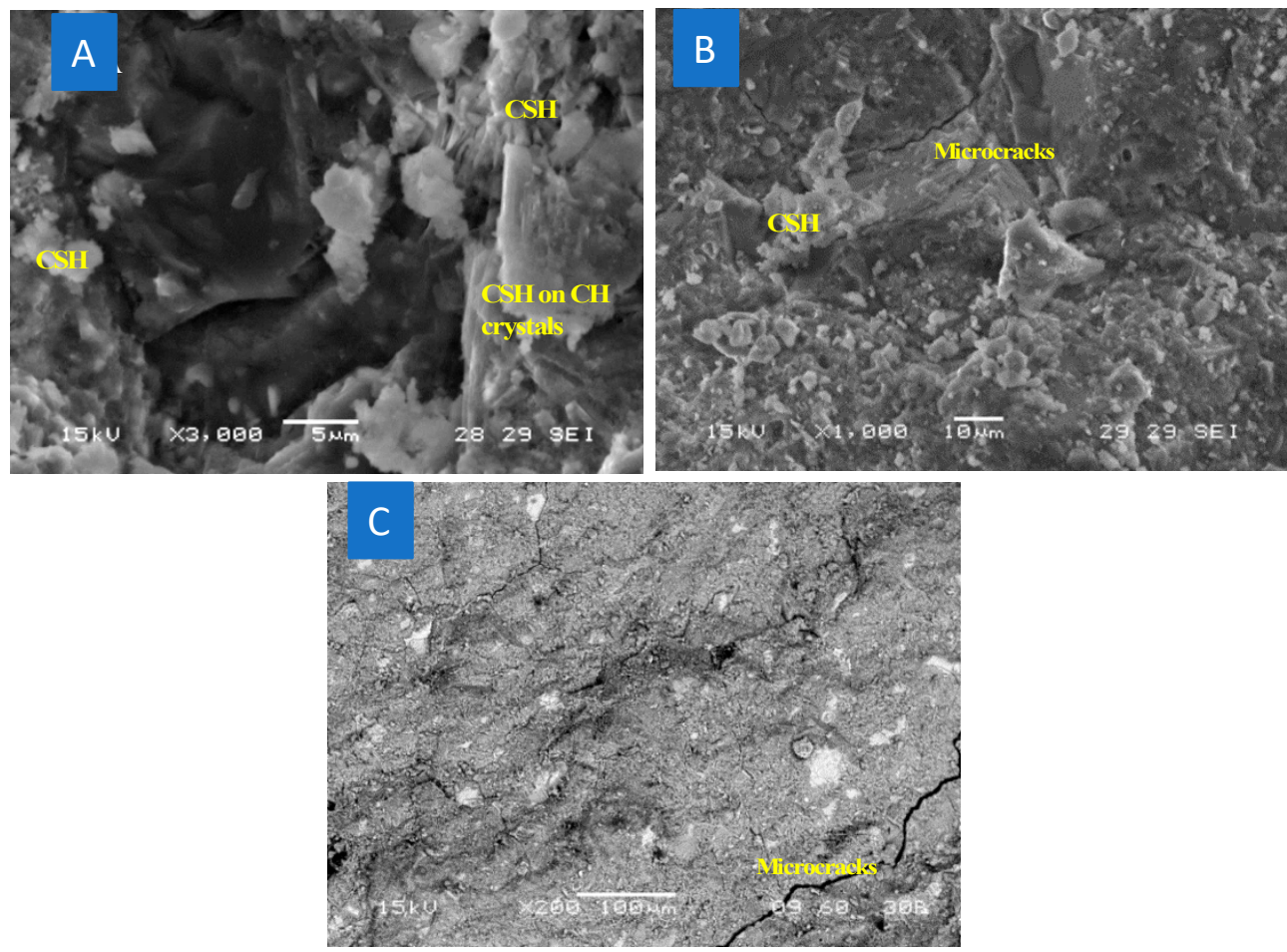

Figure 13. BSC micrograph of B1-PC86LS14 28D at (A) 3000× magnification, (B) 1000× magnification and (C) $100 \times$ magnification.
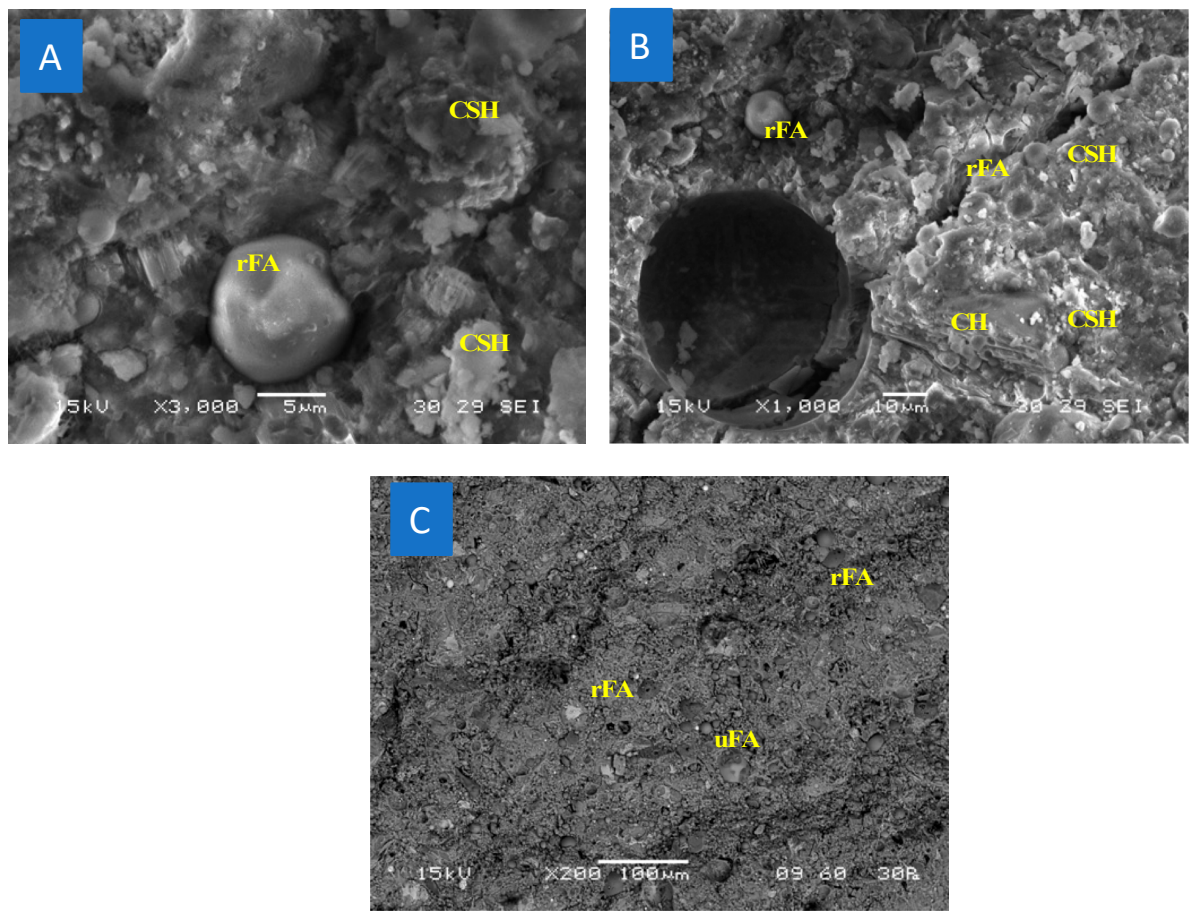

Figure 14. BSC micrograph of B7-PC60LS20FA20 28D at (A) 3000x magnification, (B) 1000x magnification [24] and (C) 100× magnification [24]. Reproduced with permission from [24], Copyright ICE Publishing, 1987. 

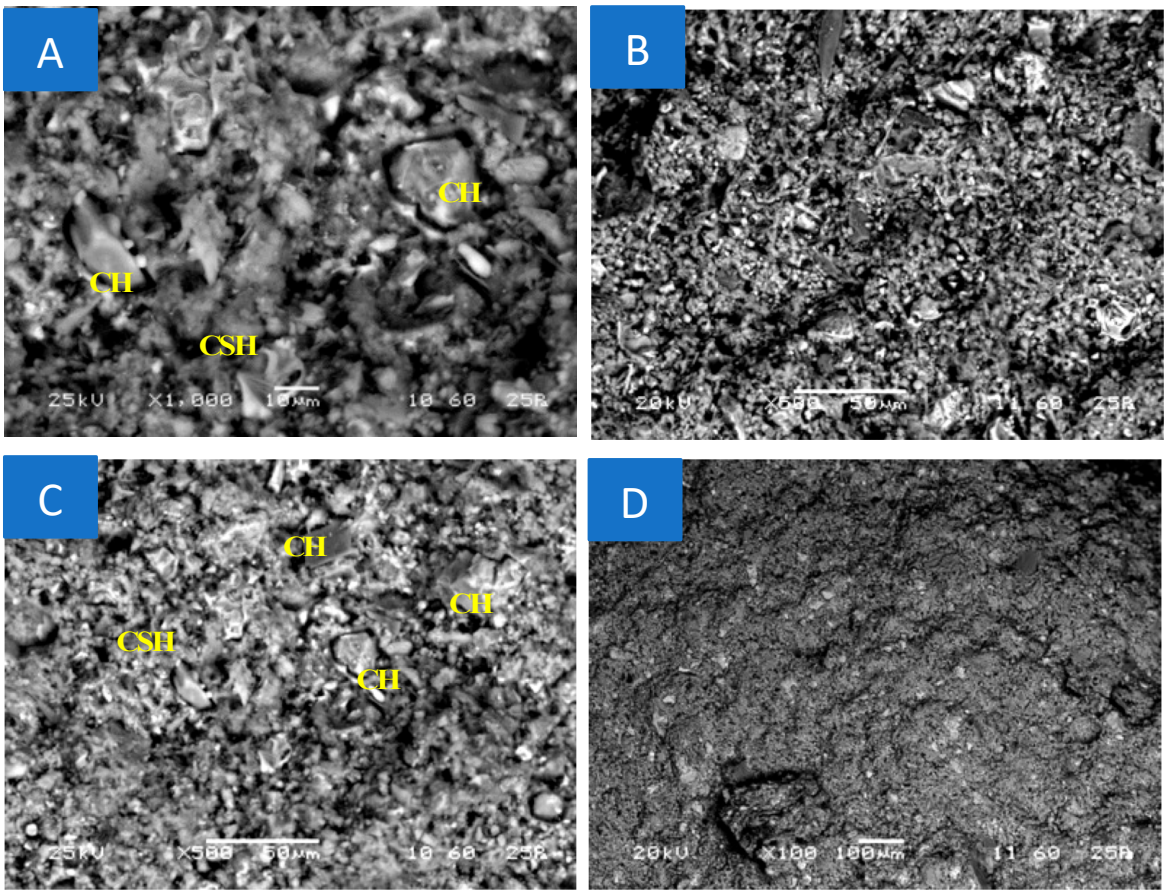

Figure 15. BSC micrograph of B10-PC60LS40 1D at (A) 1000× magnification, (B) 1000× magnification, (C) $500 \times$ magnification and (D) $100 \times$ magnification.
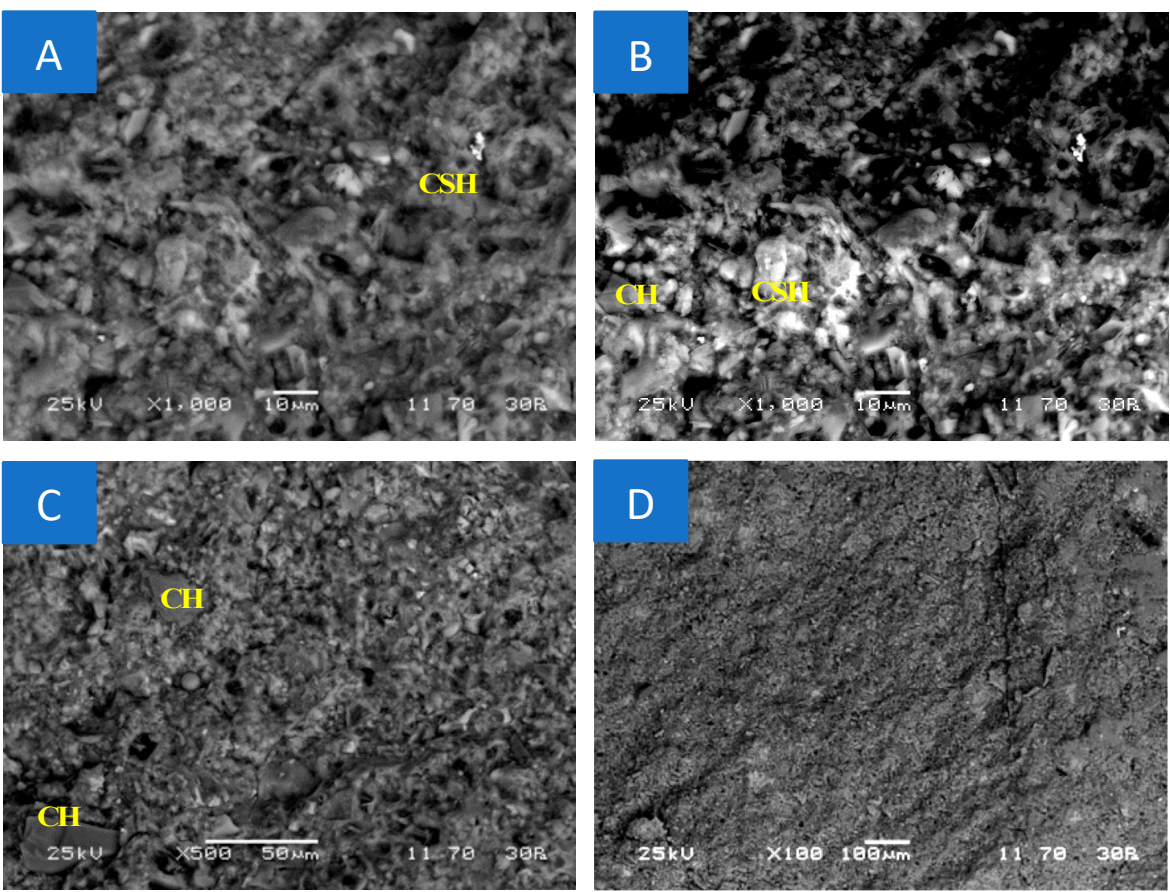

Figure 16. BSC micrograph of B10-PC60LS40 28D at (A) 1000× magnification, (B) 1000× magnification, (C) $500 \times$ magnification and (D) $100 \times$ magnification.

In Figure 14A, hydration products surrounding reacted FA (annotated as rFA) particles can be identified. In Figure 14B a common hydrated FA rim known as the "pull-out feature" was captured. It is reported as the "reminiscent" of the fully reacted FA particle [39].

Unreacted fly ash particles are annotated as uFA. Furthermore, in Figure 14B, an entire plane of $\mathrm{Ca}(\mathrm{CO})_{2}$ crystals can be distinguished above the flat plane of the rest of the surface, creating what looks 
like a crack, but in essence is the difference in levels between the two planes. In fact, in Figure 14C the entire surface is smooth and furthermore, a number of FA spherical particles can be observed.

Formulation PC60LS40 was imaged at day 1 and day 28 due to the high interest it attracted. In Figure 15, different magnifications are offered, all showing a dense, cohesive microstructure lacking microcracks, with a significant number of $\mathrm{Ca}(\mathrm{CO})_{2}$ crystals covered by $\mathrm{C}-\mathrm{S}-\mathrm{H}$ flakes. In Figure 16, a dense microstructure again filled with hydration products can be observed at different magnifications. There are no signs of microcracks, while dense areas of flake-like $\mathrm{C}-\mathrm{S}-\mathrm{H}$ are covering most parts of the micrographs. Similar images have been collected after 90 days of hydration of this specific composition [40].

\subsection{Step 4: Optimizing Quaternary Cementitious Matrices}

The first microstructural enhancement was completed with the addition of two different dosages of $\mu \mathrm{S}$ ( $5 \%$ and $10 \%$ by mass) on PC60LS20FA20, creating quaternary cementitious matrices. The results on compressive strength, $\mathrm{Ca}(\mathrm{OH})_{2}$ consumption and microstructure are shown in the following sections. Furthermore, although B8-PC45LS20FA35 showed optimum performance a slightly different paste was adopted for further optimization; PC43LS20FA37. This was decided in an effort to reduce the PC content even further. Hence, another microstructural enhancement was completed with the addition of two different dosages of $\mu \mathrm{S}$ ( $3 \%$ and $6 \%$ by mass) on PC43LS20FA37, creating another series of quaternary pastes. The results on compressive strength and $\mathrm{Ca}(\mathrm{OH})_{2}$ consumption are also shown in the following sections.

\subsubsection{Compressive Strength of Quaternary Cementitious Matrices}

As depicted in Figure 17 the addition of $\mu \mathrm{S}$ in pastes containing at least $20 \%$ FA by mass of binder is causing a retardation of the strength development, delivering lower compressive strengths. More than that, $10 \% \mu \mathrm{S}$, delay the strength gain by 28 days. These results were expected since according to CEN [41] the maximum allowable $\mu \mathrm{S}$ content in PC/ $\mu \mathrm{S}$ cements is $10 \%$ by mass. In other words, for every $1 \% \mu \mathrm{S}$ by mass, at least $9 \%$ of PC content by mass, is required so that there will be enough $\mathrm{Ca}(\mathrm{OH})_{2}$ produced by PC hydration for the $\mu \mathrm{S}$ to react with. Therefore, the $10 \% \mu \mathrm{S}$ addition was excessive and as an effect, unreacted $\mu \mathrm{S}$ particles were predicted to be distinguished by SEM investigations.

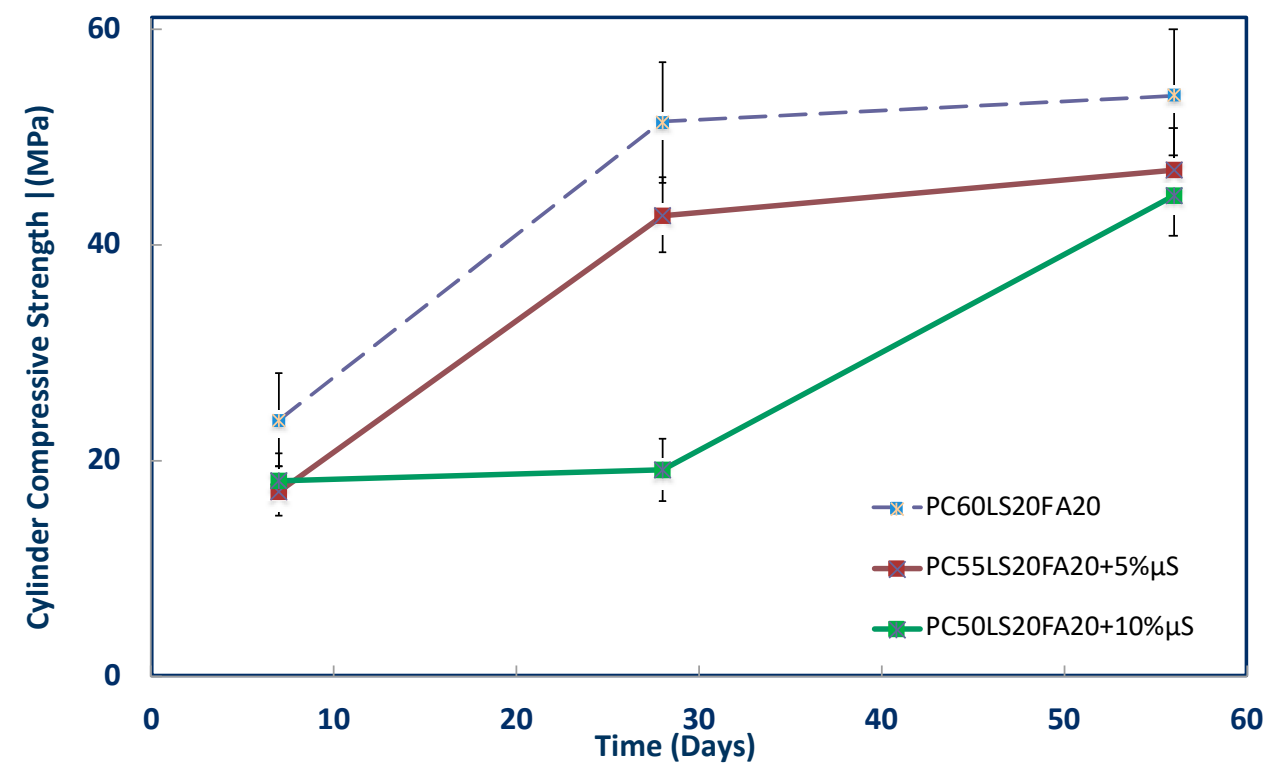

Figure 17. Cylinder compressive strength of $\mu S$ modified cementitious matrices based on PC60LS20FA20. 
As in the case of $\mu$ S enhanced PC60LS20FA20, the $\mu S$ enhanced low PC content PC43LS20FA37, showed similar compressive strength gain characteristics, although the $\mu \mathrm{S}$ content was lower in both combinations (Figure 18):

- At day 7 both series had similar starting points (about $21 \mathrm{MPa}$ for PC60LS20FA20 and $25 \mathrm{MPa}$ for PC43LS20FA37), indicating that pozzolanic reactions had already been initiated within the first 7 days.

- After day 28 the compressive strength of the reference paste is almost the same for both reference pastes, but for the $\mu \mathrm{S}$ enhanced ones, an improvement was observed. Therefore, although high LS contents are reported to be causing deterioration of the compressive strength at later ages the presence of $\mu \mathrm{S}$ offered a limited (due to the additional presence of FA) enhancement.

A marginal improvement in strength was also observed at day 1 , followed by deterioration at day 28 and 56 with respect to the reference paste. These results were in agreement with other findings, suggesting that the increasing OPC replacement is liable for the decrease in both compressive and flexural strengths [12]. The limited amount of PC and the high amount of FA present created some antagonism with the $\mu \mathrm{S}$ particles. Moreover, since for $1 \% \mu \mathrm{S}$, at least $9 \%$ of PC content by mass, is required so that the $\mu \mathrm{S}$ can react with the $\mathrm{Ca}(\mathrm{OH})_{2}$ produced by $\mathrm{PC}$ hydration for these series of pastes, the $\mu \mathrm{S}$ content should have been limited to approximately $4.8 \%$ by mass. Furthermore, knowing that for high replacements of PC with FA and LS the resulting strengths will be low, it was of particular interest to investigate if the nanoparticles could alter the performance of the low PC content blended cements, carried out in other research [42].

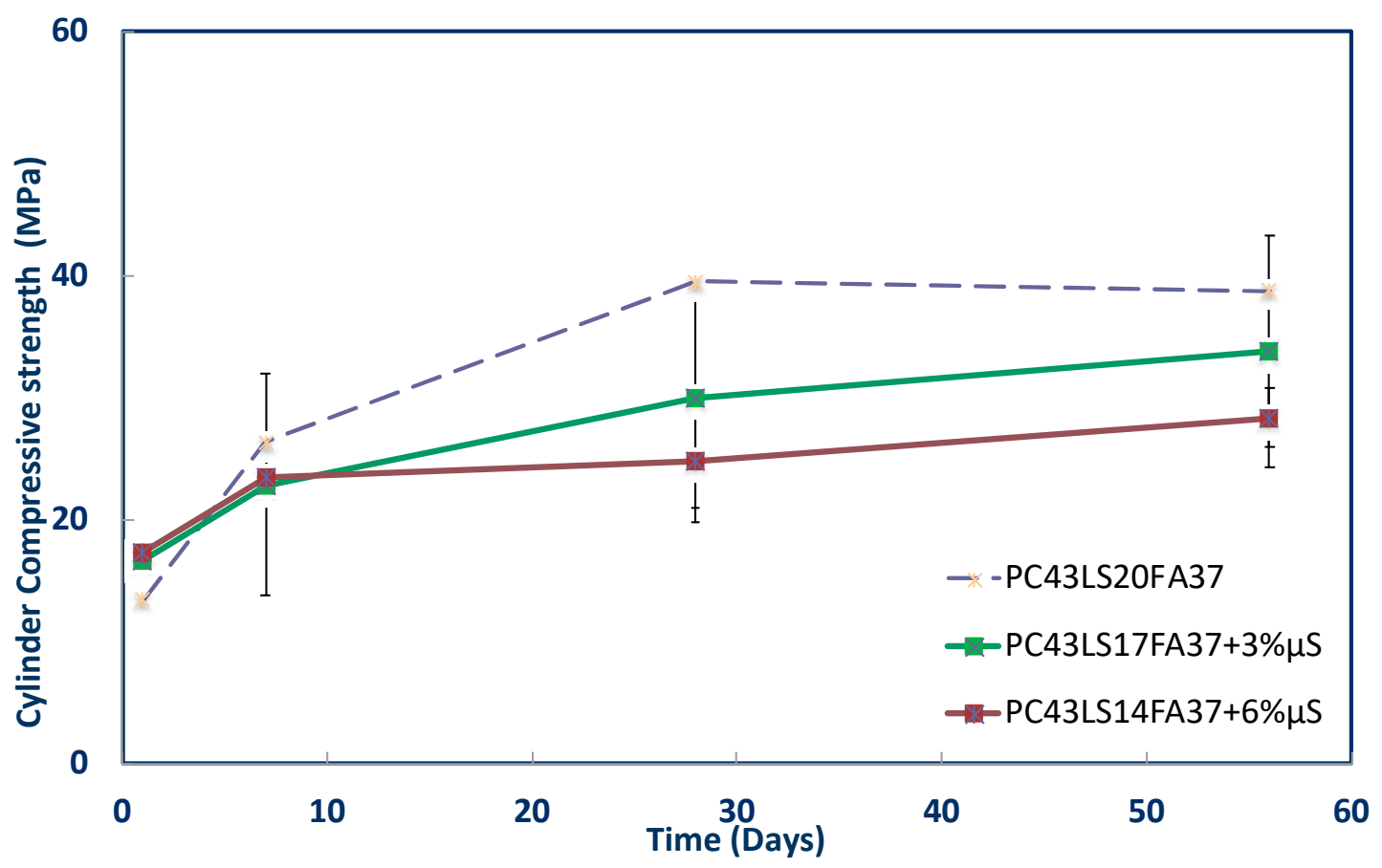

Figure 18. Cylinder compressive strength of $\mu$ S modified cement pastes based on PC43LS20FA37.

\subsubsection{Embodied $\mathrm{CO}_{2}$ of Quaternary Cementitious Matrices}

In addition to the E.CO $\mathrm{CO}_{2}$ values of PC, LS and FA pastes, the E. $\mathrm{CO}_{2}$ of $\mu \mathrm{S}$ modified pastes was also evaluated (taking as $\mu \mathrm{S}$ E. $\mathrm{CO}_{2}=14 \mathrm{~kg} \mathrm{CO}$ /tonne according to [43]. The results are presented in Table 8, where the second quaternary series based on PC43LS20FA37 had the lowest total E. $\mathrm{CO}_{2}$. Furthermore, PC43LS20FA37 exhibited the highest mechanical properties in terms of the ratio of compressive strength/E. $\mathrm{CO}_{2}$. Lastly, for such pastes the lower $\mu \mathrm{S}$ content seems to be delivering the most optimal results. 
Table 8. Embodied $\mathrm{CO}_{2}$ (kg/tonne) associated with strength of quaternary cementitious matrices.

\begin{tabular}{cccccccc}
\hline $\begin{array}{c}\text { Formulation } \\
\text { Composition }\end{array}$ & $\begin{array}{c}\text { PC } \\
\text { E.CO }_{2}\end{array}$ & $\begin{array}{c}\text { LS } \\
\text { E.CO }_{2}\end{array}$ & $\begin{array}{c}\text { FA } \\
\text { E.CO }_{2}\end{array}$ & $\begin{array}{c}\mu \text { E.CO } \\
\text { E. }\end{array}$ & $\begin{array}{c}\text { Total } \\
\text { E.CO }_{2}\end{array}$ & $\begin{array}{c}\text { Compression Strength } \\
\text { 28 Days (MPa) }\end{array}$ & $\begin{array}{c}\text { Strength/E.CO } \\
(\mathbf{M P a} / \mathbf{k g} / \text { tonne) }\end{array}$ \\
\hline PC60LS20FA20 & 558.0 & 6.4 & 0.8 & 0.0 & 565.2 & 51.3 & 0.09 \\
PC55LS20FA20+5\% $\mu \mathrm{S}$ & 511.5 & 6.4 & 0.8 & 0.7 & 519.4 & 42.7 & 0.08 \\
PC50LS20FA20+10\% $\% \mathrm{~S}$ & 466.5 & 6.4 & 0.8 & 1.4 & 475.1 & 19.1 & 0.04 \\
PC43LS20FA37 & 401.2 & 6.4 & 1.5 & 0.0 & 409.1 & 39.5 & 0.10 \\
PC43LS17FA37+3\% $\% \mathrm{~S}$ & 401.2 & 5.4 & 1.5 & 0.4 & 408.5 & 30.0 & 0.07 \\
PC43LS14FA37+6\% $\% \mathrm{~S}$ & 401.2 & 4.5 & 1.5 & 0.8 & 408.0 & 24.8 & 0.06 \\
\hline
\end{tabular}

\subsubsection{Thermal Analyses of Quaternary Cementitious Matrices}

As shown in Figure 19, given that the reference paste contained at the various ages approximately $8 \% \mathrm{Ca}(\mathrm{OH})_{2}$, a paste containing $55 \% \mathrm{PC}$ would be expected to generate $7.3 \% \mathrm{Ca}(\mathrm{OH})_{2}$ and a paste containing $50 \% \mathrm{PC}$ would be expected to generate approximately $6.6 \% \mathrm{Ca}(\mathrm{OH})_{2}$ Therefore, it can be argued that in all cases the $\mu \mathrm{S}$ addition cause a further $\mathrm{Ca}(\mathrm{OH})_{2}$ consumption. Lastly, as shown in Figure 20 no carbonation has taken place as the $\mathrm{CaCO}_{3}$ content is lower than the $20 \% \mathrm{LS}$ content present in the pastes in all combinations.

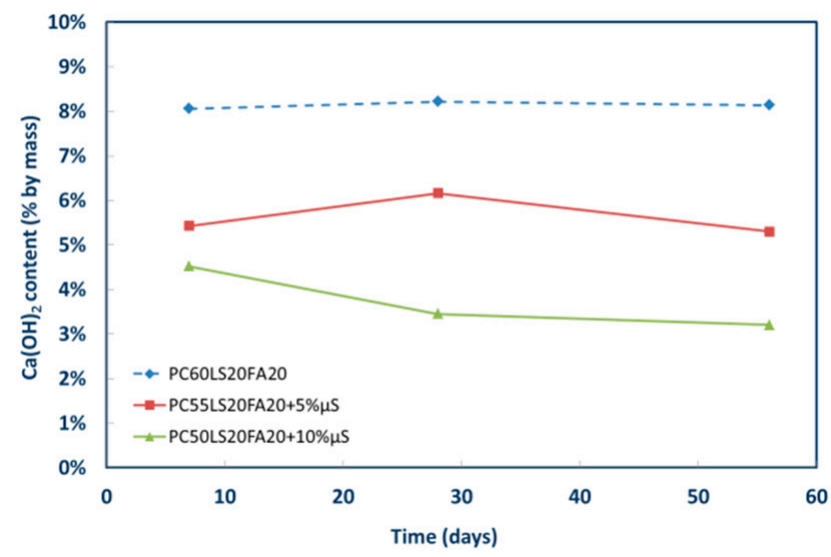

Figure 19. $\mathrm{Ca}(\mathrm{OH})_{2}$ content $\mu \mathrm{S}$ modified cementitious matrices based on PC60LS20FA20.

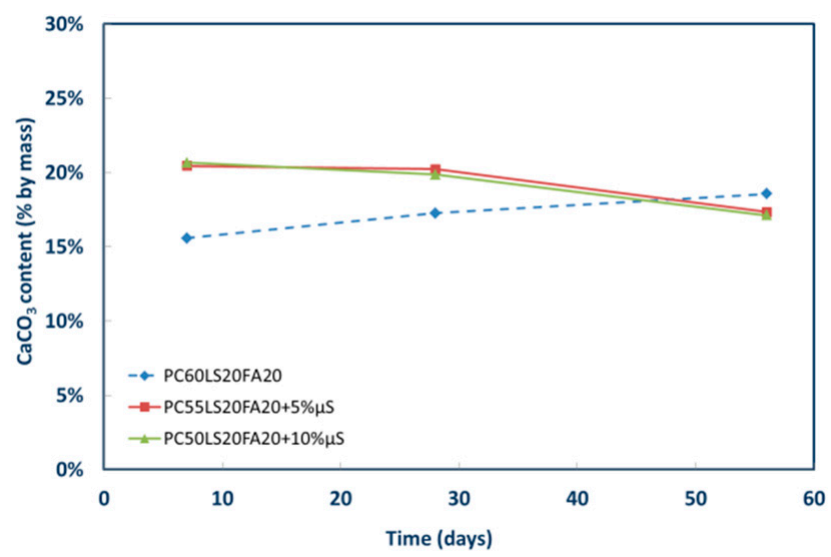

Figure 20. $\mathrm{CaCO}_{3}$ content of $\mu \mathrm{S}$ modified cementitious matrices based on PC60LS20FA20.

The $\mathrm{Ca}(\mathrm{OH})_{2}$ consumption is depicted in Figure 21. It is interesting to note that after day 28 and by day 56 , the $\mathrm{Ca}(\mathrm{OH})_{2}$ content in the reference paste reduced to $1.5 \%$ by mass. It has been reported that for high PC replacement by FA $(>60 \%)$, depletion of $\mathrm{Ca}(\mathrm{OH})_{2}$ may be observed after one year $[16,17]$. Therefore, given more time, $\mathrm{Ca}(\mathrm{OH})_{2}$ in this ternary system is expected to be depleted, if the sample has not carbonated. However, the phenomena observed in composite cements can be more complex. 
In fact, it has been reported that combinations containing $65 \%$ OPC and $35 \%$ of a formulation of FA and LS produced similar amounts of $\mathrm{Ca}(\mathrm{OH})_{2}$ after day 1 . However, the minimum amount of $\mathrm{Ca}(\mathrm{OH})_{2}$ was reached for the 30\% FA and 5\% LS formulation and not the 35\% FA formulation [12]. This was attributed to the synergistic interaction of FA and LS. Although according to De Weerdt et al. [12] the presence of LS leads to the formation of carboaluminate hydrates, this was not detected by the TG analyses (Figure 22), neither by the XRD analyses shown in detail in other publication [25].

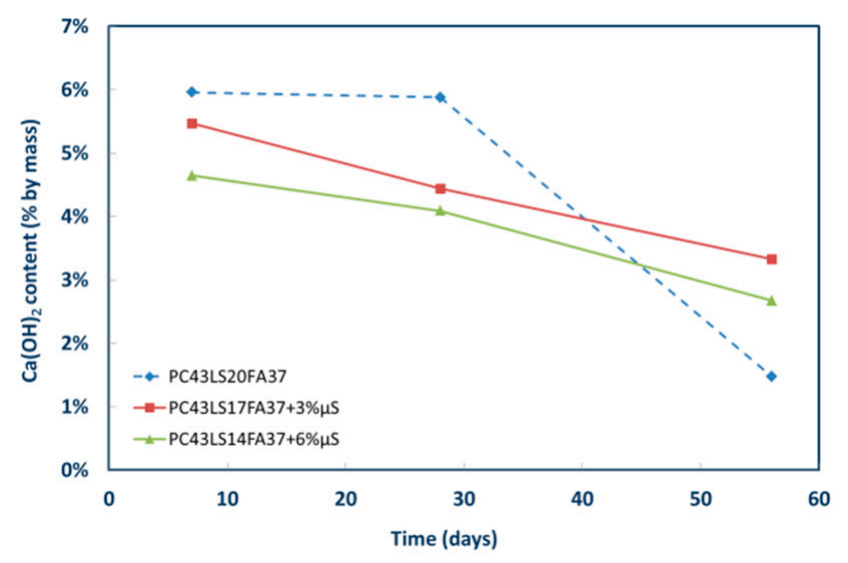

Figure 21. $\mathrm{Ca}(\mathrm{OH})_{2}$ content $\mu \mathrm{S}$ modified cementitious matrices based on PC43LS20FA37.

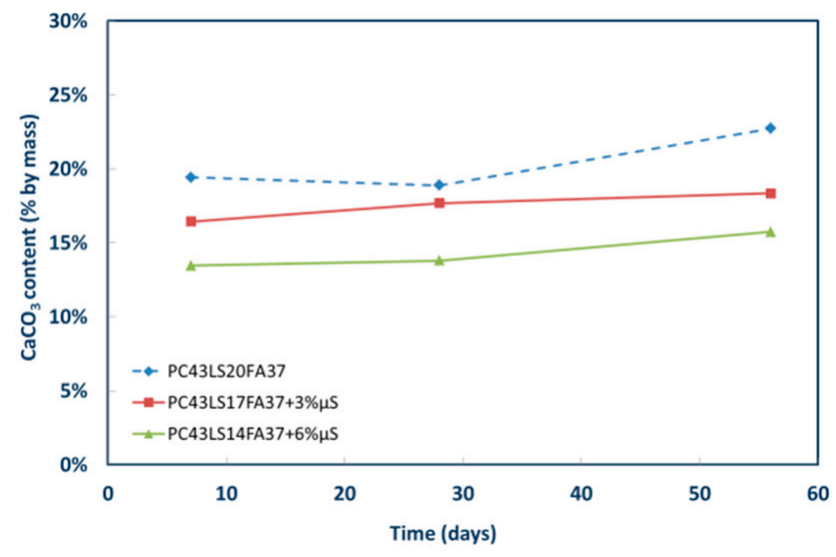

Figure 22. $\mathrm{CaCO}_{3}$ content of $\mu \mathrm{S}$ modified cementitious matrices based on PC43LS20FA37.

\subsubsection{Microstructural Characterization of Quaternary Cementitious Matrices}

Indicatively, four BSC micrographs of PC55LS20FA20 $+5 \% \mu \mathrm{S}$ are shown in Figure 23. As discussed earlier in Portland limestone cement pastes with high FA contents except for the needle-like hydration products (Figure $23 \mathrm{C}, \mathrm{D}$ ), $\mathrm{CaCO}_{3}$ flakes and $\mathrm{Ca}(\mathrm{OH})_{2}$ crystals a number of rims and reacted $\mathrm{FA}$ particles can be detected. It is interesting to note that the investigation of different areas did not yield indications of unreacted FA particles. A fact correlating well with the TG measurements showing that there was enough $\mathrm{Ca}(\mathrm{OH})_{2}$ still present in the hydrated paste after day 28 and 56 should the FA have needed it to react with. Reacted FA (rFA) particles are circled in Figure 23B. Furthermore, in Figure 23B the reaction of a FA particle leaving a characteristic mullite sphere [39] was identified (enclosed in the rectangle). It was suggested by $\mathrm{Xu}$ and Sarkar that the glass phase in FA has been reacted and the crystalline phase is left almost intact. Adding to this, the typically acicular hydration product of FA in the first 28 days can be seen in Figure 23B (enclosed in a rectangle). Lastly, the presence of microcracks is prominent, possibly signaling cracking due to elevated heat of hydration. Therefore, this specific formulation could be enhanced by reducing the silica fume content. 
Comparing the reference paste PC60LS20FA20 (Figure 14) with the 5\% $\mathrm{\mu S}$ (Figure 23) and the 10\% $\mu \mathrm{S}$ (Figure 24) enhanced quaternary formulations and particularly the 200 times magnification there is an indication that the $\mu \mathrm{S}$ enhanced pastes are less dense. This cannot be attributed to particle packing that is expected to be enhanced, but credited to the high amount of FA present. The FA was already feeding from the $\mathrm{Ca}(\mathrm{OH})_{2}$, therefore the more reactive pozzolanic particles of $\mu \mathrm{S}$ may not be able to access the $\mathrm{Ca}(\mathrm{OH})_{2}$ crystals encapsulated within the reacted FA particles. That is to say, although $\mathrm{Ca}(\mathrm{OH})_{2}$ is not depleted in these quaternary formulations, the $\mu \mathrm{S}$ particles may be deactivated by the inaccessibility of $\mathrm{Ca}(\mathrm{OH})_{2}$ created by the hydration products around the much greater quantities of $\mathrm{FA}$.
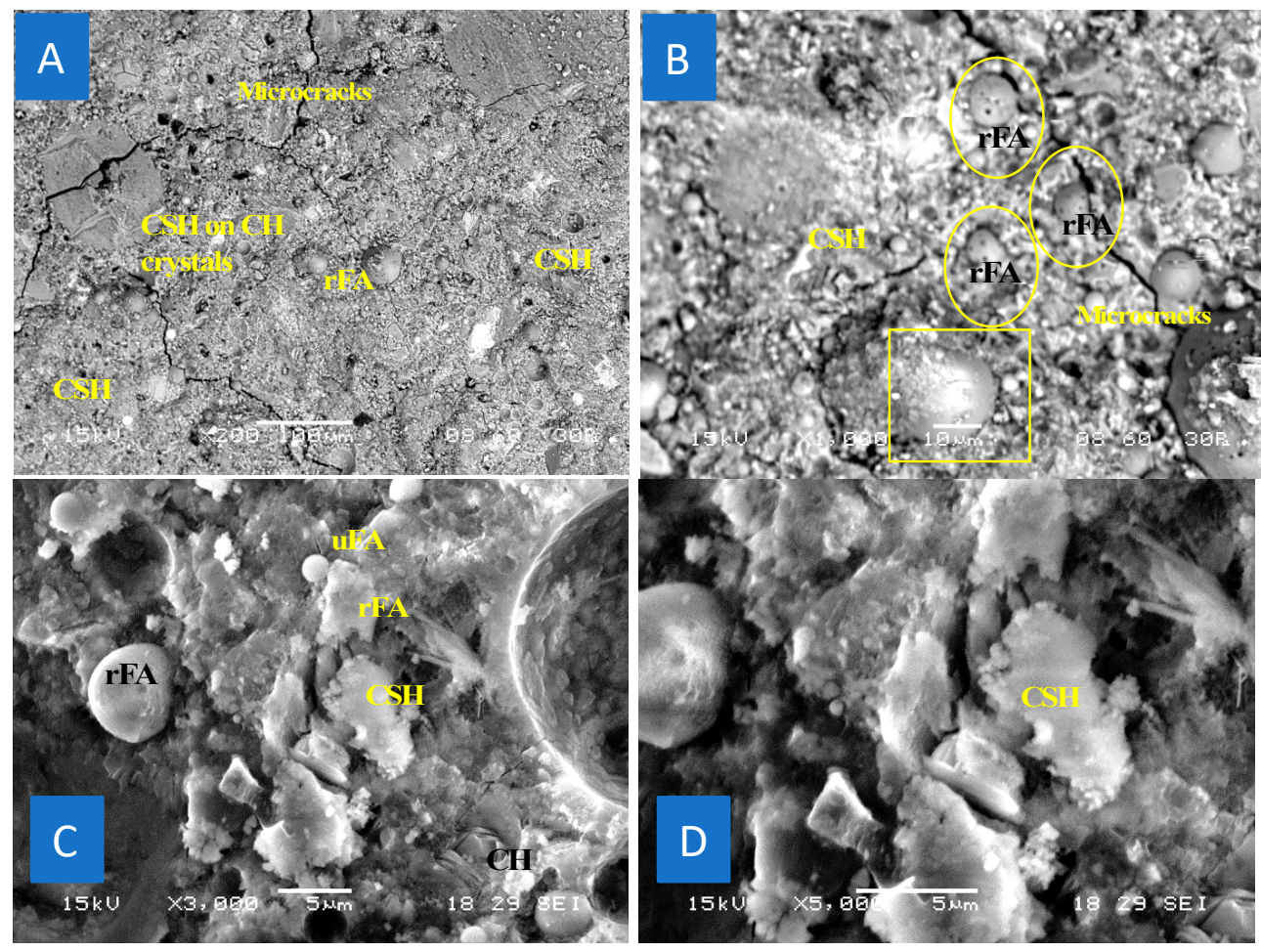

Figure 23. BSC micrograph of PC55LS20FA20+5\% HS at 28D at (A) $200 \times$ magnification, (B) $1000 \times$ magnification, (C) 3000× magnification and (D) 5000× magnification.

As depicted in Figure 24, a similar microstructure to the lower $\mu \mathrm{S}$ content paste can be observed. The only difference being the plethora of needle-like hydration products detected at all magnifications and the many unreacted $\mu \mathrm{S}$ particles (small, spherical bright elements). The typically acicular hydration product of FA in the first 28 days can be seen in Figure $24 \mathrm{~B}$ (enclosed in a rectangle). Another FA particle with hydration gel around it, is circled in Figure 23C. Reacted FA particles are circled in Figure 24C. In agreement with Lothenbach et al. [16], the $\mu \mathrm{S}$ enhanced pastes showed a more refined pore structure, but are expected to deliver higher total porosities. That is to say, capillary pores were expected to be reduced and finer pores slightly increased. This could partly explain the microcracks present in the images taken. The increased heat of hydration could be the other reason for the development of microcracks as discussed for the $+5 \% \mu \mathrm{S}$ addition. Knowing that the presence of the cracks is related to lower durability of the formulations, future research on quaternary pastes using this formulation should contain substantially lower $\mu \mathrm{S}$ contents. In fact, this observations led to the reduction of the $\mu \mathrm{S}$ contents in the design of the quinary combinations, based on PC43LS20FA37. As shown in published research four different formulations competed against the reference paste PC43LS20FA37; (a) PC43LS17FA37 + $2.5 \% \mu \mathrm{S}+0.5 \% \mathrm{nS}$ (where $\mathrm{nS}$ is the abbreviation for nanoparticles of $\mathrm{SiO}_{2}$ ), (b) PC43LS17FA37 $+2.0 \% \mu \mathrm{S}$ $+1.0 \% \mathrm{nS}$, (c) PC43LS14FA37 $+5.5 \% \mu \mathrm{S}+0.5 \% \mathrm{nS}$ and (d) PC43LS14FA37 $+5.0 \% \mu \mathrm{S}+1.0 \% \mathrm{nS}$ [42] The lower additions of $\mathrm{nS}$ particles performed better, however, the presence of high quantities of pozzolanic and highly pozzolanic materials, delayed hydration reactions and strength gain. In other 
words, the nanoparticles were unable to leverage the already expected delayed reactions due to the presence of high volume fly ash and silica fume content.
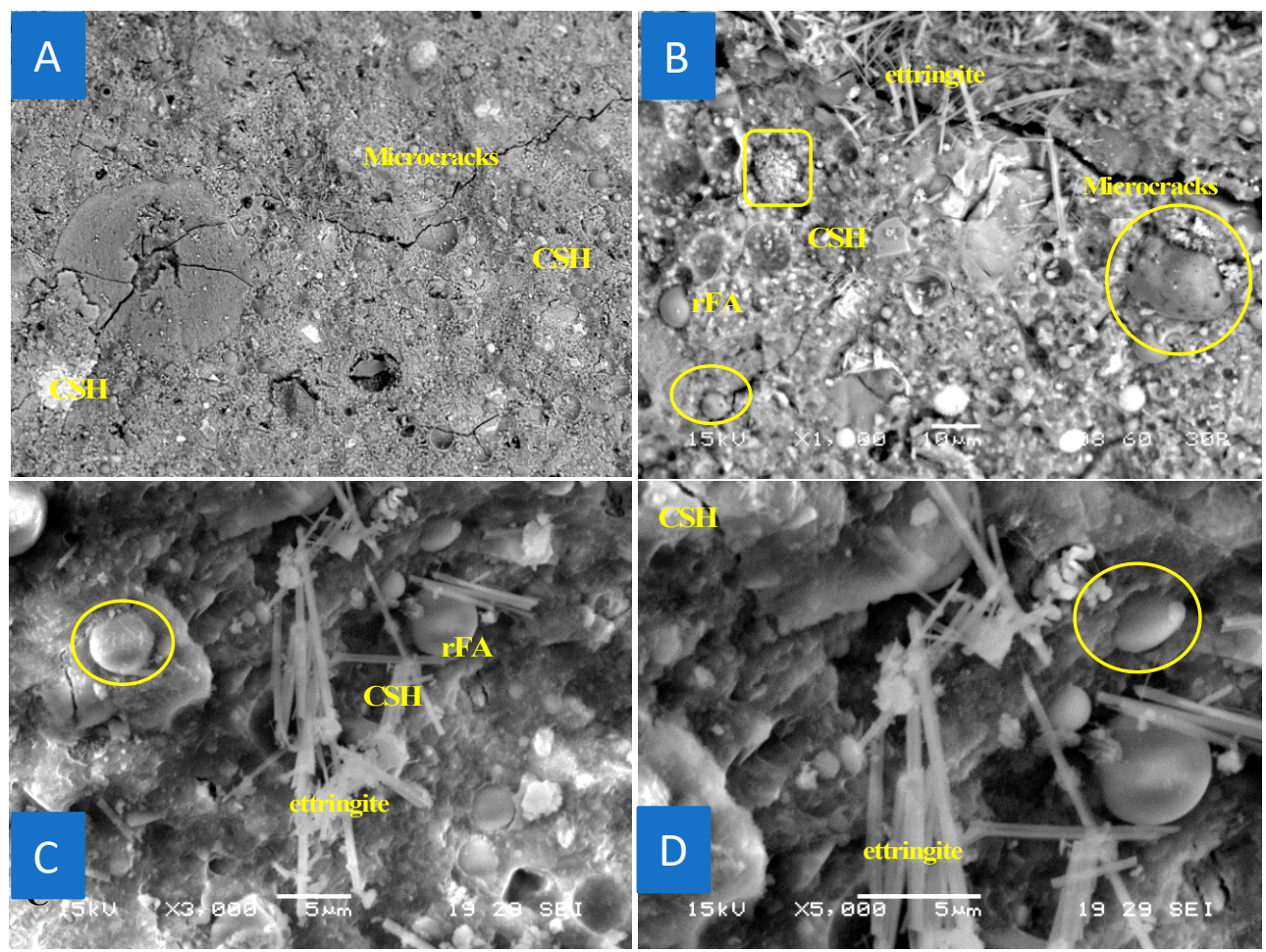

Figure 24. BSC micrograph of PC50LS20FA20 $+10 \% \mu$ S at $28 \mathrm{D}$ at (A) $200 \times$ magnification, (B) $1000 \times$ magnification, (C) 3000× magnification and (D) 5000× magnification.

The BSC micrograph of PC43LS20FA37 at day 28 is presented below (Figure 25). A number of reacted and unreacted particles, can be observed as expected according to the TG analyses which lead to the conclusion that at this age almost half of the FA particles were still unreacted), $\mathrm{CaCO}_{3}$ flakes and $\mathrm{Ca}(\mathrm{OH})_{2}$ crystals were also present and areas of dense matter, believed to be $\mathrm{C}-\mathrm{S}-\mathrm{H}$. Similar description is valid for curing until day 1 and day 56 [42]. No cracks can be observed, rendering the specific formulation promising for further optimization.
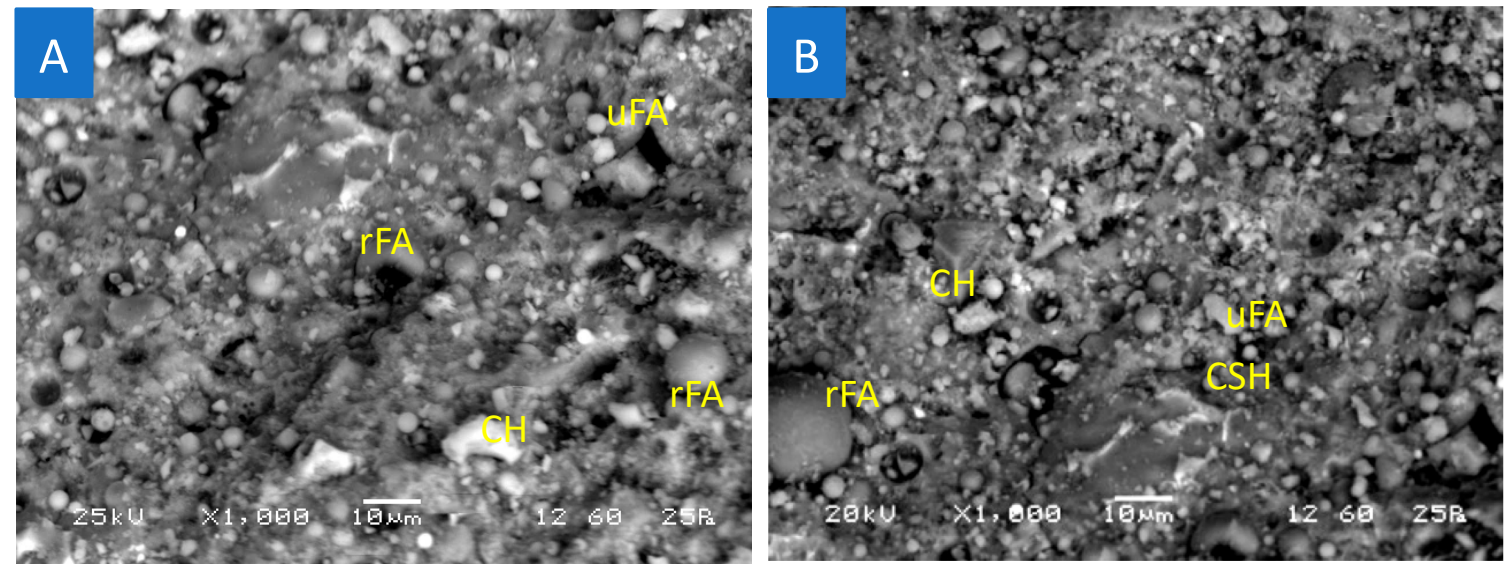

Figure 25. BSC micrograph of PC43LS20FA37 at 28D at (A) 1000x magnification and (B) 1000× magnification. 


\section{Conclusions}

The present paper is the last part of an extensive research program carried out at the University of Bath, aimed at investigating the effect of nanoparticles in sustainable blended cements. Although a significant number of papers have been published on the effect of various nanoparticles on low carbon footprint composite cementitious formulations $[5,8,10,25,27-30,40,42,44-47]$, the starting pastes and the methodology of selecting formulation on performance based criteria, has never been discussed before. The paper has introduced, analyzed, compared and discussed, a suite of binary (PC + LS) and ternary $(\mathrm{PC}+\mathrm{FA}+\mathrm{LS})$ cementitious matrices. Three ternary pastes were selected which were further optimized with the addition of silica fume. Competing constituents and areas of improvements to pave the way for the addition of the nanoparticles were identified. Moreover, the pozzolanic reactivity in ternary and quaternary cement paste formulations was investigated, while the lowest possible Portland cement content was employed. In addition to the above, a number of further conclusions were made:

- Current research can expand on challenging formulations, which allow for significant reduction in $\mathrm{CO}_{2}$ emissions, beyond allowable limits by current codes.

- It was demonstrated that optimizing blended or composite Portland cement pastes at high PC replacement levels is an iterative process. This step by step methodology presented in the paper can serve as a basis for other researchers in the field.

- In areas where pozzolanic materials are scarce, binary formulations can be developed as the control mix, further enhanced by highly reactive materials, such as nanoparticles of $\mathrm{SiO}_{2}$ or montmorillonite $[10,29,44,47]$.

- In areas where fly ash is abundant and needs to be valorized, ternary blends can be developed and again can be further enhanced with nanomaterials [22,25,42]. Similarly, quinary cementitious matrices can be developed with both micro- and nanosized silica [42] for superior strength and denser microstructure.

- It is essential that material characterization is thorough and extensive testing is necessary.

- The complicated interaction between the constituents was investigated with respect to strength development, changes in the hydration reaction and microstructural enhancement.

Lastly, adding to the future research suggestions, apart from the addition of different types of nanoparticles for strength and durability improvements, which has been previously mentioned, matrices containing different types of supplementary cementitious materials can be generated. Some options could include ground granulated blast furnace slag or geopolymers altering water demand, strength and microstructural characteristics. This research has rendered the surpassing of the boundaries defined by the current codes of practice, possible and therefore, further optimizations of blended pastes can be expected in the near future.

Author Contributions: Conceptualization, S.P. and K.P.; methodology, S.P.; validation, S.P. and K.P.; formal analysis, S.P. investigation, S.P.; data curation, S.P.; writing-original draft preparation, S.P.; writing-review and editing, S.P. and K.P.; funding acquisition, K.P. Both authors have read and agreed to the published version of the manuscript. All authors have read and agreed to the published version of the manuscript.

Funding: This research was funded by European Commission funding, FIBCEM project, grant Number 262954.

Acknowledgments: The authors acknowledge the European Commission funding and all partners are thanked for their input and for the supply of materials. The authors would also like to acknowledge the Department of Chemical Engineering at the University of Bath for the use of the TG analyzer. The strength over embodied $\mathrm{CO}_{2}$ calculations of pastes (shown in the respective columns in Tables 6 and 8) were carried out by Dr Juliana Calabria-Holley and her help is greatly appreciated. The particle size distribution results of the four constituent materials were prepared by colleagues in Maulana Azad National Institute of Technology (MANIT), Bhopal, India with funding provided by the UK-India Education and Research Initiative (UKIERI) Program.

Conflicts of Interest: The authors declare no conflict of interest. 


\section{References}

1. IEA-WBCSD. Cement Technology Roadmap 2009 Carbon Emissions; IEA-WBCSD: Paris, France, 2009; Available online: https://www.iea.org/pdf/technology/WBCSD-IEA_CementRoadmap.pdf (accessed on 15 March 2020).

2. American Concrete Institute. ACI 232.2R-18 Use of Fly Ash in Concrete; American Concrete Institute: P.O. Box 9094, Farmington Hills, MI 48333-9094, USA, 2018.

3. Obla, H.; Lobo, C.L. Prescriptive Specifications-A Reality Check. 2015. Available online: https://www. nrmca.org/Research_Engineering/Documents/11.pdf (accessed on 15 March 2020).

4. Sobolev, K.; Gutiérrez, M.F. How nanotechnology can change the concrete world: Part one of a two-part series. Am. Ceram. Soc. Bull. 2005, 84, 14.

5. Papatzani, S.; Paine, K.; Calabria-Holley, J. A comprehensive review of the models on the nanostructure of calcium silicate hydrates. Constr. Build. Mater. 2015, 74, 219-234. [CrossRef]

6. Kalpokaitè-Dičkuvienè, R.; Lukošiūtè, I.; Čèsnienè, J.; Brinkienė, K.; Baltušnikas, A. Cement substitution by organoclay-The role of organoclay type. Cem. Concr. Compos. 2015, 62, 90-96. [CrossRef]

7. Brinkienè, K.; Čèsnienè, J.; Lukošiūtè, I.; Baltušnikas, A.; Kalpokaitè-Dičkuvienè, R. Effect of organoclay addition on durability related properties of cement pastes. Fresenius Environ. Bull. 2015, 24, 2624-2629.

8. Calabria-Holley, J.; Papatzani, S.; Naden, B.; Mitchels, J.; Paine, K. Tailored montmorillonite nanoparticles and their behaviour in the alkaline cement environment. Appl. Clay Sci. 2017, 143, 67-75. [CrossRef]

9. Papatzani, S. Nanotechnologically Modified Cements: Effects on hydration, Microstructure and Physical Properties. PhD Thesis, University of Bath, Bath, UK, 2014.

10. Papatzani, S.; Paine, K.; Calabria-Holley, J. The effect of the addition of nanoparticles of silica on the strength and microstructure of blended Portland cement pastes. In Proceedings of the 2014 International Concrete Sustainability Conference, Boston, MA, USA, 12-15 May 2014.

11. Palomo, A.; Monteiro, P.; Martauz, P.; Bilek, V.; Fernandez-Jimenez, A. Hybrid binders: A journey from the past to a sustainable future (opus caementicium futurum). Cem. Concr. Res. 2019, 124, 105829. [CrossRef]

12. de Weerdt, K.; Kjellsen, K.O.; Sellevold, E.; Justnes, H. Synergy between fly ash and limestone powder in ternary cements. Cem. Concr. Compos. 2011, 33, 30-38. [CrossRef]

13. Skibsted, J.; Snellings, R. Reactivity of supplementary cementitious materials (SCMs) in cement blends. Cem. Concr. Res. 2019, 124, 105799. [CrossRef]

14. Vance, K.; Aguayo, M.; Oey, T.; Sant, G.; Neithalath, N. Hydration and strength development in ternary portland cement blends containing limestone and fly ash or metakaolin. Cem. Concr. Compos. 2013, 39, 93-103. [CrossRef]

15. Rong, Z.D.; Sun, W.; Xiao, H.J.; Wang, W. Effect of silica fume and fly ash on hydration and microstructure evolution of cement based composites at low water-binder ratios. Constr. Build. Mater. 2014, 51, 446-450. [CrossRef]

16. Lothenbach, B.; Scrivener, K.; Hooton, R.D. Supplementary cementitious materials. Cem. Concr. Res. 2011, 41, 1244-1256. [CrossRef]

17. de Weerdt, K.; Ben Haha, M.; Le Saout, G.; Kjellsen, K.O.; Justnes, H.; Lothenbach, B. Hydration mechanisms of ternary Portland cements containing limestone powder and fly ash. Cem. Concr. Res. 2011, 41, $279-291$. [CrossRef]

18. Wongkeo, W.; Thongsanitgarn, P.; Chindaprasirt, P.; Chaipanich, A. Thermogravimetry of ternary cement blends. J. Therm. Anal. Calorim. 2013, 113, 1079-1090. [CrossRef]

19. Hossain, M.M.; Karim, M.R.; Hasan, M.; Hossain, M.K.; Zain, M.F.M. Durability of mortar and concrete made up of pozzolans as a partial replacement of cement: A review. Constr. Build. Mater. 2016, 116, 128-140. [CrossRef]

20. BSI. BS EN 197-1:2011: Cement. Part 1: Composition, Specifications and Conformity Criteria for Common Cements; BSI: London, UK, 2011.

21. BSI. BS EN 196-1:2005 Methods of Testing Cement. Determination of Strength; BSI: London, UK, 2005, 36p.

22. Calabria-Holley, J.; Paine, K.; Papatzani, S. Effects of nanosilica on the calcium silicate hydrates in Portland cement-fly ash systems. Adv. Cem. Res. 2015, 27, 187-200. [CrossRef]

23. Zhang, J.; Scherer, G.W. Comparison of methods for arresting hydration of cement. Cem. Concr. Res. 2011, 41, 1024-1036. [CrossRef] 
24. Struble, L.; Livesey, P.; Del Strother, P.; Bye, G. Portland Cement; ICE Publishing: London, UK, 2011. [CrossRef]

25. Papatzani, S.; Paine, K. Polycarboxylate/nanosilica-modified quaternary cement formulations-Enhancements and limitations. Adv. Cem. Res. 2018, 30, 256-269. [CrossRef]

26. Scrivener, K.L.; Füllmann, T.; Gallucci, E.; Walenta, G.; Bermejo, E. Quantitative study of Portland cement hydration by X-ray diffraction/Rietveld analysis and independent methods. Cem. Concr. Res. 2004, 34, 1541-1547. [CrossRef]

27. Papatzani, S. Effect of nanosilica and montmorillonite nanoclay particles on cement hydration and microstructure. Mater. Sci. Technol. 2016, 32, 138-153. [CrossRef]

28. Papatzani, S.; Paine, K. Inorganic and organomodified nano-montmorillonite dispersions for use as supplementary cementitious materials-A novel theory based on nanostructural studies. Nanocomposites 2017, 3, 2-19. [CrossRef]

29. Papatzani, S.; Paine, K. Lowering cement clinker: A thorough, performance based study on the use of nanoparticles of $\mathrm{SiO} 2$ or montmorillonite in Portland limestone nanocomposites. Eur. Phys. J. Plus 2018, 133, 430. [CrossRef]

30. Papatzani, S.; Badogiannis, E.G.; Paine, K. The pozzolanic properties of inorganic and organomodified nano-montmorillonite dispersions. Constr. Build. Mater. 2018, 167, 299-316. [CrossRef]

31. BCA. Fact Sheet 18 [Part 1]—Embodied CO2 of UK Cement, Additions and Cementitious Materials. 2009. Available online: www.cementindustry.co.uk (accessed on 15 March 2020).

32. Grist, E.R.; Paine, K.A.; Heath, A.; Norman, J.; Pinder, H. The environmental credentials of hydraulic lime-pozzolan concretes. J. Clean. Prod. 2015, 93, 26-37. [CrossRef]

33. Xu, A.; Sarkar, S.L.; Nilsson, L.-O. Effect of fly ash on the microstructure of cement mortar. Mater. Struct. 1993, 26, 414-424. [CrossRef]

34. Sobolev, K.; Tabatabai, H.; Zhao, J.; Flores, I.; Muzenski, S.; Oliva, M.G.; Rose, J. Superhydrophobic Engineered Cementitious Composites for Highway Bridge Applications: Technology Transfer and Implementation; University of Wisconsin-Milwaukee: Milwaukee, WI, USA; University of Wisconsin-Madison: Madison, WI, USA, 2013.

35. Tishmack, J.K.; Olek, J.; Diamond, S. Characterization of High-Calcium Fly Ashes and Their Potential Influence on Ettringite Formation in Cementitious Systems. Cem. Concr. Aggregates 1999, 21, 82-92.

36. Jones, R.; McCarthy, M.; Newlands, M. Fly Ash route to low embodied CO2 and implications for concrete construction. In 2011 WOCA Proceedings Papers; University Press of Kentucky: Lexington, KY, USA, 2011.

37. MPA. Specifying Sustainable Concrete-Understanding the Role of Constituent Materials. 2011. Available online: www.sustainableconcrete.org.uk (accessed on 15 March 2020).

38. Feldman, R.F.; Carette, G.G.; Malhotra, V.M. Studies on mechanics of development of physical and mechanical properties of high-volume fly ash-cement pastes. Cem. Concr. Compos. 1990, 12, 245-251. [CrossRef]

39. Xu, A.; Sarkar, S.L. Microstructural development in high-volume fly-ash cement system. J. Mater. Civ. Eng. 1994, 6, 117-136. [CrossRef]

40. Papatzani, S.; Grammatikos, S.; Adl-Zarrabi, B.; Paine, K. Pore-structure and microstructural investigation of organomodified/Inorganic nano-montmorillonite cementitious nanocomposites. AIP Conf. Proc. 2018, 1957, 030004. [CrossRef]

41. CEN. Cement_Part 1: Composition, Specifications and Conformity Criteria for Common Cements; EN 197-1:2000; CEN: Brussels, Belgium, 2011.

42. Papatzani, S.; Paine, K. Optimization of Low-Carbon Footprint Quaternary and Quinary (37 \% Fly Ash) Cementitious Nanocomposites with Polycarboxylate or Aqueous Nanosilica Particles. Adv. Mater. Sci. Eng. 2019, 2019, 5931306. [CrossRef]

43. Grist, E.; Paine, K.; Heath, A.; Pinder, H. An Investigation into the Viability and Benefits of Modern Hydraulic Lime Concretes. In Innovations in Concrete Construction; Dhir, R.K., Singh, S.P., Goel, S., Eds.; Excel India Publishers: New Delhi, India, 2013; pp. 967-981.

44. Papatzani, S.; Paine, K. Dispersed Inorganic or Organomodified Montmorillonite Clay Nanoparticles for Blended Portland Cement Pastes: Effects on Microstructure and Strength. In Nanotechnology in Construction; Sobolev, K., Shah, S.P., Eds.; Springer International Publishing: Cham, Switzerland, 2015; pp. 131-139. [CrossRef]

45. Papatzani, S.; Paine, K. Construction, demolition and excavation waste management in EU/Greece and its potential use in concrete. Fresenius Environ. Bull. 2017, 26, 5572-5580. 
46. Papatzani, S.; Grammatikos, S.; Paine, K. Permeable Nanomontmorillonite and Fibre Reinforced Cementitious Binders. Materials (Basel) 2019, 12, 3245. [CrossRef] [PubMed]

47. Papatzani, S.; Paine, K. From Nanostructural Characterization of Nanoparticles to Performance Assessment of Low Clinker Fiber-Cement Nanohybrids. Appl. Sci. 2019, 9, 1938. [CrossRef]

(C) 2020 by the authors. Licensee MDPI, Basel, Switzerland. This article is an open access article distributed under the terms and conditions of the Creative Commons Attribution (CC BY) license (http://creativecommons.org/licenses/by/4.0/). 